\title{
The Effects of Protected Beams and Their Connections on the Fire Resistance of Composite Buildings
}

\author{
Shuyuan Lin ${ }^{1}$, Zhaohui Huang ${ }^{2 *}$, Mizi Fan ${ }^{3}$ \\ Department of Mechanical, Aerospace and Civil Engineering, Brunel University London, \\ Uxbridge, UB8 3PH, UK
}

\begin{abstract}
According to full-scale fire tests, it is noticed that tensile membrane action within the concrete floor slabs plays an important role in affecting the fire resistance of composite buildings. It is well known that the development of tensile membrane actions relies on the vertical support along the edges of the slab panel. However, there is at present a lack of research into the influence of vertical supports on the tensile membrane actions of the floor slabs. In this paper, the performances of a generic three dimensional $45 \mathrm{~m} \times 45 \mathrm{~m}$ composite floor subjected to ISO834 Fire and Natural Fire are investigated. Different vertical support conditions and three steel meshes are applied in order to assess the impact of vertical supports on tensile membrane action of floor slabs. Unlike other existing large scale modelling which assumes the connections behave as pinned or rigid for simplicity, two robust 2-node connection element models developed by the authors are used to model the behaviour of endplate and partial end-plate connections of composite structures under fire conditions. The impact of connections on the 3D behaviour of composite floor is taken into consideration. The load-transfer mechanisms of composite floor when connections fail due to axial tension, vertical shear and bending are investigated. Based on the results obtained, some design recommendations are proposed to enhance the fire resistance of composite buildings.
\end{abstract}

Keywords: Steel Connection, Fire Resistance, Composite floor, Finite Element Modelling, Tensile Membrane Action.

\section{Highlights:}

Model a large scale, $45 \mathrm{~m}$ x 45m, composite frame under different fire conditions.

$>$ Systematically investigate the impact of the connections for protected beams on the tensile membrane actions of supported floor slabs.

$>$ Understand the influence of the vertical deflections of protected beams on the tensile membrane action of the floor slabs.

$>$ Analyse the effects of different reinforcement details of the floor slabs on the performance of composite floor under different fire conditions.

\footnotetext{
1 PhD Research Student. Email: Shuyuan.Lin@ brunel.ac.uk

${ }^{2 *}$ Corresponding author: Reader, Email: Zhaohui.Huang@brunel.ac.uk

3 Professor, Email: Mizi.Fan@brunel.ac.uk
} 


\section{Introduction}

Significant progress has been made in analysing the performance of steel framed composite buildings under fire conditions over the last decades. The most common and conventional way of retaining the strength and stiffness of steel-framed buildings under fire conditions, is to provide fire protection to all exposed steel members. However, observations from a series of full-scale Cardington fire tests have shown that steel framed composite structures can provide a significantly greater fire resistance than is suggested by standard fire tests on isolated structural members [1]. This appeared to be due to an interaction between the heated members within the fire compartment, the concrete floor slabs and the connected steel frame structure. If steel members within the structures loss strength and stiffness rapidly due to high temperatures, alternative load paths would be adopted to transfer load for the remaining part of the structures. Experimental and analytical investigations involving full-scale fire tests indicated that tensile membrane action within the concrete floor slabs plays an important role in enhancing the fire resistance of composite buildings. The load carrying capacity of slab due to tensile membrane action is significantly higher than the slab under pure bending [2]. Tensile membrane action can occur when the slabs undergoes large vertical displacements. As shown in Fig.1, the induced radial tension in the centre of the slab is balanced by a peripheral ring of compression [3]. The occurrence of tensile membrane action mainly relies on the conditions of vertical support maintained around the edges of the slab panel. To utilize the tensile membrane action, the composite floors need to be divided into slab panels, consisting of an array of steel beams. The beams around the perimeter of the slab panels are protected, while the internal secondary beams can be left unprotected.

Up to now, research has focused on the influence of the tensile membrane actions on the fire resistance of composite floors, with the assumption that the fully vertical supports along the perimeter of the slab panel are provided by protected beams. Different design methods have been developed to simulate the behaviour of composite slab at elevated temperatures incorporating tensile membrane action [4-12]. However, there is as yet a lack of detail research into the influence of the vertical deflections of protected beams during fire on the tensile membrane actions of the slab panel. For the majority of previous research on modelling composite floor subjected to fire, the beam-to-column and beam-to-beam connections were assumed to behave either as pinned or rigid for simplicity, and the vertical shear and axial tension failures of the connection were not taken into account [13, 14]. However, under fire conditions due to the loads transferred from unprotected beams to the 
protected beams, the vertical loads acting on the connections of the protected beams may increase to beyond the design capacity of vertical shear resistance of the connections. Hence, a proper connection model is needed to predict the failure of the connections due to vertical shear loads.

This paper presents a comprehensive study conducted on a generic three dimensional 45m x 45m composite building, with realistic loading conditions and structural layout, under different fire conditions. A series of analyses has been carried out using different support conditions on floor slab panels and slab reinforcement details. In this research, it is assumed that the beam-to-column and beam-to-beam connections behave as semi-rigid. The end-plate connections are used to connect primary beams to columns. The partial end-plate connections are adopted to connect secondary beams to columns, and primary beams to secondary beams, respectively. These two types of the connections are modelled using the simplified connection models developed by the authors $[15,16]$. The proposed two connection models have good numerical stability under a static solver condition, and can be used for large scale modelling of composite buildings in fire. The main objectives of this study are:

- To systematically investigate the impact of the connections for protected beams on the tensile membrane actions of supported floor slabs, in which the failure of the connections due to axial tension, vertical shear or bending is considered.

- To understand the influence of the vertical deflections of protected beams on the tensile membrane action of the floor slabs.

- To analyse the effects of different reinforcement details of the floor slabs on the performance of composite floor under different fire conditions.

\section{Theoretical background of the software VULCAN}

In this study, the finite element software VULCAN is employed, which is capable to model the three dimensional performance of composite and steel-framed buildings under fire conditions [17-19]. The software VULCAN has been developed through long term research, and has been extensively validated against available experimental results. VULCAN has also been used in many real projects for structural fire engineering design. As shown Fig.2, in this program the steel-framed composite buildings are modelled as an assembly of finite beamcolumn, connection and slab elements. It is assumed that the nodes of these different types of 
element are defined in a common reference plane that is assumed to coincide with the midsurface of the concrete slab element, whose location is fixed throughout the analysis.

The beam-columns are modelled using 3-node line elements [19]. The cross-section of each element is divided into a number of segments to allow the required variation of the distributions of temperature, stress, and strain. Both geometric and material non-linearities are included. The reinforced concrete slabs are represented using 9-node nonlinear layered elements, in which the membrane action of the floor slabs is considered $[17,18]$. The slab elements are divided into a number of plain concrete and reinforcing steel layers. The temperature and material properties for each layer can be specified independently. An effective stiffness model was developed to model the ribbed nature of typical composite slabs [20]. For modelling composite steel decking concrete floor slabs, a maximum-strain failure criterion is applied for plain concrete layers, and the concrete layers are considered to be orthotropic after the initiation of cracking.

Recently, two robust simplified connection models have been developed by the authors [15, 16] for modelling the end-plate and partial end-plate connections between steel beams and columns in fire. The proposed models are based on the two-node connection element framework developed by Huang [21]. In order to assess the influence of the axial ductility of connection on the connection's axial forces and deflection of the connected beam, five different levels of axial stiffness of connection were used to represent pinned and rigid connections for modelling of steel frame at elevated temperatures [21]. The numerical analyses indicated that axial stiffness of the connection has a very limited influence on the deflection of the connected beam and negligible influence on the axial tensile forces of the connection [21]. Hence, in Huang's model the axial deformability of the connection is ignored. This assumption is retained in the current two connection models used in this study.

These models have been incorporated into software Vulcan. The brief descriptions of the connection models are given in the following.

\subsection{Simplified major-axis connection models}

For modelling the behaviour of connections which connect beam to flange of column (majoraxis) at elevated temperatures, two simplified connection models were developed $[15,16]$ and incorporated into software VULCAN. As described in Reference [15], a simplified model has been proposed to predict the performance of flush and extended end-plate beamto-column flange (major-axis) connections in fire. The connections failure due to bending, 
axial tension, compression and vertical shear are all taken into account, as well as the impact of axial tensile force of the connected beam on the connection. Validation results showed that the proposed model is capable of predicting the performances of flush and extended endplate connections under fire conditions with reasonable accuracy.

Another simplified 2-node connection element model for simulating the behaviour of partial end-plate beam-to-column flange (major-axis) connections under fire conditions is presented in Reference [16]. The two stage rotational behaviour of partial end-plate connection is taken into consideration, including the performance of the connections after the beam bottom flange comes into contact with the column flange. Connection failures due to bending, axial tension, compression, and vertical shear are taken into account. The validation results demonstrated that the proposed model is capable to precisely predict the performance of partial end-plate connections between steel beams and column flange at both ambient and elevated temperatures.

\subsection{Simplified minor-axis partial end-plate connection model}

For minor axis connections between steel beam and column web, or secondary beam and the web of primary beams, it is generally to assume these connections behave as pinned. In reality however, the great majority of connections behave as semi-rigid. The minor-axis connection behaves differently from the major-axis connection, as the column web resists the tension and compression forces produced from the beam flanges in bending [22]. Lima et al. [23] proposed a finite element model to simulate the behaviour of a minor-axis connection consisting of double web angles, a seat angle, or a transverse web stiffener welded to the column web. The initial stiffness of the whole connection was assessed using the component-based method, which requires defining the active basic components within the connection. Compared to the typical major connection component-based model, a new basic component of column web in bending was taken into consideration.

At present, Eurocode 3 only provides guidance for designing connections between a steel beam and column flange. Given that there are no existing code provisions for semi-rigid minor axis partial end-plate connections, a simplified model is proposed here - in accordance with the general principles provided in Eurocode EN1993-1-8 [24] for modelling minor-axis partial end-plate connections in fire. The main frame of the 2-node connection element model for partial end-plate beam-to-column flange connections [16] is adopted here, with 
developments to incorporate the behaviour of a new basic component of the column web in bending into the model.

To implement the new component of column web in bending into the simplified partial endplate connection model developed in Reference [16] the initial stiffness and resistance of this component should be determined. The initial stiffness of column web component is calculated according to the mechanical model proposed by Lima et al. [23], regarding the column web as a plate supported at the junction with the flanges and free in the other borders. The initial stiffness can be expressed as:

$$
k_{c w, \min o r}=\frac{16 t_{w c}^{3} E_{c w}}{L_{c w, \min o r}^{2}}\left(\frac{\alpha+(1-\beta) \tan (35-10 \beta)}{(1-\beta)^{3}+\frac{10.4(1.5-1.63 \beta) t_{w c}^{2}}{L_{c w, \min o r}^{2}}}\right)
$$

where $E_{c w}$ is the Young's modulus of column web, $t_{w c}$ is the thickness of column web.

$$
\begin{aligned}
& L_{c w, \min o r}=h_{c}-2 t_{f c}-1.5 r_{c} \\
& \alpha=\frac{k}{L_{c w, \min o r}} \quad \text { for } 0.05 \leq \alpha \leq 0.2 \\
& \beta=\frac{w_{b}+k}{L_{c w, \min o r}} \quad \text { for } 0.08 \leq \beta \leq 0.75
\end{aligned}
$$

$h_{c}$ is the depth of the column cross-section, $t_{f_{c}}$ is the thickness of column flange, $r_{c}$ is the column fillet radius, $k$ is the max width of tension bolts across comers, $w_{b}$ is the bolt gauge between the centrelines.

The tension resistance of column web component is obtained based on SCI P358 [25], which can be defined as:

$$
\begin{aligned}
& F_{c w, \min o r, \text { tens }}=\frac{8 M_{p l, R d, u}}{1-\beta_{1}}\left(\eta_{1}+1.5\left(1-\beta_{1}\right)^{0.5}\left(1-\gamma_{1}\right)^{0.5}\right) \\
& M_{p l, R d, u}=\frac{f_{u, c} t_{w c}^{2}}{4 \gamma_{M, u}} \text { with } \gamma_{M, u}=1.1 \\
& \beta_{1}=\frac{w_{b}}{L_{c w, \min o r}}
\end{aligned}
$$




$$
\begin{aligned}
& \gamma_{1}=\frac{d_{0}}{L_{c w, \min o r}} \\
& \eta_{1}= \begin{cases}\frac{p(r)-d_{0}}{L_{c w, \min o r}} & \text { for } r=1 \\
\frac{p(r)-0.5 d_{0}}{L_{c w, \min o r}} & \text { for } r \neq 1\end{cases}
\end{aligned}
$$

where $f_{u, c}$ is the ultimate tensile strength of the column, $d_{0}$ is the diameter of bolt hole, $r$ is the bolt row number, $p(r)$ is the vertical spacing between tension bolt rows.

The two-node major-axis connection element model, presented in Reference [16], were fully validated and will be used, in this study, for modelling the connections between the primary beams and columns. Also this major-axis connection element is modified with the new component described above to produce a new two-node minor-axis connection element for modelling the partial end-plate connections between beam to column web, or secondary beam to the web of primary beam in fire. However, due to lack of experimental data available on minor-axis partial end-plate connections between steel beam and column web or beam web at elevated temperatures, the proposed model cannot be validated against test results. Hence, as an alternative, the tests on major-axis partial end-plate connections used in Reference [16, 26] were modified here to represent minor-axis connections with the same geometry of the connection tested in Reference [27].

The tests results of the major-axis partial end-plate connections produced in Reference [27] were used to compare against the predictions of the minor-axis connection model developed here, in with the both connections have the same geometry. In the tests [27] a force, with an inclined angle $(\theta)$ to the axis of the connected beam, was applied. This applied force generated moment, vertical shear and axial tension forces on the connection tested. Three different inclined angles were employed, where $\theta=35^{\circ}, 45^{\circ}$ and $55^{\circ}$. These angles represented different combination of vertical shear and axial tension forces. All fire tests were conducted by uniformly heating the specimen to the specified temperature, then gradually increasing load until connection failure.

Figs 3 to 5 show the predictions of the current minor-axis model, together with both the test results and predictions of the major-axis partial end-plate connections [16, 26, 27]. Fig. 3 shows the comparison results of the ambient temperature test EP_20_45_07-09-07. It is noticed that the minor-axis model developed here is capable of predicting the second stage 
rotational behaviour of partial end-plate connection when the beam bottom flange comes into contact with the column web. Figs 4 and 5 illustrate the comparison results for test $\mathrm{EP}_{-}$ 450_35_11-05-07 at $450^{\circ} \mathrm{C}$, and test EP_650_55_11-07-07 at $650{ }^{\circ} \mathrm{C}$, respectively. It is evident that the predicted results generated by minor-axis model developed here are closed to the predictions of major-axis model.

This means that the strength and stiffness of minor-axis partial end-plate connections are similar to the major-axis connections with the same geometry. This may be the reasons why current design codes, such as Eurocode 3 only provides guidance for designing major-axis partial end-plate connections between steel beam and column flange. Therefore, in this study it is reasonable to assume that the proposed minor axis partial end-plate connection model can be used to represent the partial end-plate connections between steel beams and column web and beam web, in order to investigate the behaviours of steel framed composite building in fire.

As described above the steel-framed composite buildings are modelled as an assembly of finite beam-column, connection and slab elements. It is assumed that the steel beam and reinforced concrete floor are fully composited. Also the thermal expansions and contractions of steel and concrete due to the temperature changes are considered in the steel beam and reinforced concrete slab elements. In these models the steel regains its stiffness and strength during cooling phase of a natural fire. But the concrete cannot regain its stiffness and strength after cooling. Therefore the effect of the cooling phase in a natural fire on the behaviours of steel beams, floor slabs and connections and their interactions are fully considered in the model. It is clear that large tensile forces occur in the connections during the cooling phase of a natural fire. The developed connection models described above can predict the axial tension failures of the connection due to the large tensile forces generated within the connected beams during the cooling phase of a natural fire.

\section{Analysis of 3D composite frame under different fire conditions}

A series of numerical studies have been conducted on a generic three dimensional $45 \mathrm{~m} \times 45 \mathrm{~m}$ composite building, under two typical fire conditions. As shown in Fig. 6, the floor consists of five $9 \mathrm{~m} \times 9 \mathrm{~m}$ bays in each direction. For steel beam members within the frame, the section of 533x210x92UB was used for the primary beam, while size of 356x127x39UB was adopted for the secondary beam with S355 steel. The column of size 305x305x97UC was applied with a height of $4.5 \mathrm{~m}$. The lightweight concrete composite floor had an overall depth 
of $130 \mathrm{~mm}$, with PMF CF70 metal decking. It was assumed that the composite frame was designed for an office building, and two hours fire resistance was required. The realistic design load for this building was assumed as follows:

- Self-weight of composite slab: $2.08 \mathrm{kN} / \mathrm{m}^{2}$

- Self-weight of steel: $0.2 \mathrm{kN} / \mathrm{m}^{2}$

- Raised floor, services and ceiling: $0.8 \mathrm{kN} / \mathrm{m}^{2}$

- Partitions: $1.0 \mathrm{kN} / \mathrm{m}^{2}$

- Imposed load: $2.5 \mathrm{kN} / \mathrm{m}^{2}$

At the fire limit state, the total design load is $6.1 \mathrm{kN} / \mathrm{m}^{2}$, with the applied partial load factors of 1.0 for dead loads, and 0.8 for non-permanent imposed loads. Flush end-plates connections (major-axis) were applied to connect the primary beam-to-column flange. Partial end-plate connections (minor-axis) were used to connect the secondary beams to the columns' web, and secondary beams to the web of primary beams. The configurations of flush endplate and partial end-plate connections are illustrated in Fig. 7. For a flush end-plate connection, section of $573 \times 250 \times 25$ was used with six M24 Grade 8.8 bolt rows. Among the six bolt rows, four of them were designed to resist axial tensile force, while the rest two bolt rows functioned as shear bolt rows. The vertical shear resistance of the connection at ambient temperature is $542 \mathrm{kN}$. For a partial end-plate connection, a size of $230 \times 150 \times 10$ was applied with three M24 Grade 8.8 bolt rows. Two of these bolt rows were assumed to be tension bolt rows, while the other one was designed to resist vertical shear force. The vertical shear resistance of the connection at ambient temperature is $271 k N$. Hence, the load ratio related to vertical shear for secondary beam is 0.3 , while for the primary beam it is 0.15 .

In this study, two different fire scenarios were adopted: ISO 834 Fire and Natural Fire. The Natural Fire was defined using a parametric temperature-time curve, calculated according to EN 1993-1-2 [28]. The 'office' usage class was assumed. The calculation considered the size of compartment, the given fire load, the assumed air ventilation condition, and the amount of combustibles. It was assumed that two hours fire resistance was required. The main purpose for using a typical natural fire here is to give a comparison against ISO 834 Fire. Hence, to investigate the influence of different parametric fires on the behaviour of the composite building is out of the scope of the current paper. In the current study all columns, 
primary beams and secondary beams along the column grid lines were fire protected, and all internal secondary beams were left unprotected.

Fig. 8 shows the temperatures of unprotected beams, protected beams and columns with time. The maximum temperatures designed for unprotected secondary beams are $1047^{\circ} \mathrm{C}$ and $915^{\circ} \mathrm{C}$ respectively, under ISO 834 Fire and Natural Fire conditions. During the cooling phases of the Natural Fire scenario, the designed minimum temperature is $114^{\circ} \mathrm{C}$. For protected beams and columns, the maximum temperatures are less than $600^{\circ} \mathrm{C}$ and $550^{\circ} \mathrm{C}$, respectively. The temperatures of connections were assumed to be $80 \%$ of the temperatures of the connected beams. As for slabs, the temperatures were calculated along the thickness using a finite element program developed by Huang et al. [29]. The concrete slab was divided into fourteen layers. Each layer had a different uniform temperature distribution. It was assumed that the reinforcement was positioned just above the metal decking. The temperatures of the top, middle, and bottom concrete layers of slab and steel mesh under ISO 834 Fire and Natural Fire are illustrated in Fig. 9.

As shown in Fig. 6, in this research only one quarter of the frame (two and half $(9 \mathrm{~m} \times 9 \mathrm{~m})$ bays in each direction) was analysed, in order to save computing time by taking the advantage of symmetry. It was assumed that the whole ground floor of the building was under fire. A total of 8 cases were analysed in this study. They are: using three different steel meshes (A142, A252 and A393) under two different fire scenarios (6 cases); using geometric linear slab element with A393 mesh under ISO Fire condition (1 case); all protected beams fixed vertically with A142 mesh under ISO fire condition (1 case). In the following sections the reference temperatures for all figures are related to the temperatures of unprotected secondary beams within the fire compartment.

\subsection{The impact of the connections}

The first two cases were analysed using a A142 steel mesh for floor slabs, under ISO 834 Fire and Natural Fire conditions respectively. Figs 10 and 11 show the predicted vertical shear forces of the partial end-plate connections against temperature and time, for protected secondary beams at the positions B2, C2, B3 and C3 (see Fig. 6) under ISO Fire and Natural Fire, respectively. These four connections connect the protected secondary beams to columns. It can be clearly seen from the results that all the four connections failed due to vertical shear under two fire scenarios. As can be seen in Fig. 10, under ISO Fire condition, the vertical shear forces acting on the partial end-plate connections at B2, C2, B3 and C3 ranged from 50 
to $60 \mathrm{kN}$ at ambient temperature, which is less than $25 \%$ of the vertical shear resistance of the connections used. When temperatures of unprotected secondary beams were higher than $400{ }^{\circ} \mathrm{C}$, these beams gradually lost their loading capacity, and the loads on the floor slabs were redistributed from the hot beams to the protected beams.

Due to the composite decking slab is almost one way spanning in ribbed direction, hence the vertical load transfer mechanism is: the vertical loads on slab floor are transferred to secondary beams first, then to primary beams or columns. Hence, under fire conditions when the temperatures of unprotected secondary beams are high, all vertical loads are redistributed to protected secondary beams along the column grid lines. In this case, the theoretical vertical load at the connection of the protected secondary beam should be $247 \mathrm{kN}$. As shown in Fig. 10, when the unprotected beam temperature reached to $725^{\circ} \mathrm{C}$, the vertical shear forces acting on the partial end-plate connections at B2 and B3 increased to $267 k N$, exceeding the vertical shear resistance of the connections at the elevated temperatures (the vertical shear resistance of the connection is $271 \mathrm{kN}$ at ambient temperatures). The difference of the predicted and theoretical vertical loads at the connections is $20 \mathrm{kN}$. This is due to the relatively loose tolerance used in the modelling in order to save the computing time for this large scale analysis. Therefore, the connections positioned at B2 and B3 failed by vertical shear. The vertical supports of the protected secondary beams B2-C2 and B3-C3 were lost. When the temperature approached around $850{ }^{\circ} \mathrm{C}$, the partial end-plate connections located at C2 and C3 failed due to the vertical shear. Then the vertical supports of the protected secondary beams C2-D2 and C3-D3 were also lost.

The vertical shear resistance of the partial endplate connections used here is defined as the minimum value of the shear resistance of the bolts in shear and the plate in bearing. The results of the analysis indicated that the shear failures modes of the connections were all due to the bolts in shear. After the vertical supports of the protected secondary beams were lost, the vertical loads originally supported by protected beams were transferred through the concrete slab to the primary beams at the column's position. The protected beams still behave with concrete slab as composite beams. This is why a sudden increase of beam/slab deflection which is not seen from the deflection plots.

Similar load transfer mechanism can be observed from the results under the Natural Fire condition (see Fig. 11). When temperatures reached $400^{\circ} \mathrm{C}$, unprotected secondary beams started to lose strength and stiffness. Then with the increasing of temperature, more loads were redistributed from the unprotected secondary beams to the protected beams. The 
applied vertical shear forces exceeded the shear resistances of partial end-plate connections located at B2 and B3 when the temperatures were around $600^{\circ} \mathrm{C}$. After that, the partial endplate connections positioned at $\mathrm{C} 2$ and $\mathrm{C} 3$ also failed by vertical shear when temperature was around $750^{\circ} \mathrm{C}$.

Figs 12 and 13 show the deflections versus temperatures and times at position P1, P2, P3, and P4 (see Fig. 6), under ISO 834 Fire and Natural Fire scenarios respectively. As shown in Fig. 6, the positions of $\mathrm{P} 1$ and $\mathrm{P} 2$ are located at the mid-span of protected secondary beams, B1-C1 and B2-C2, while P3 and P4 are positioned at the centres of the compartments. It can be observed that the deflections at the mid-span of the protected beams increased significantly, when the temperature of unprotected beams was beyond $800{ }^{\circ} \mathrm{C}$. Therefore, the vertical support for the floor slab panels, provided by the protected beams, was significantly reduced. As illustrated in the deflection profiles at $1008{ }^{\circ} \mathrm{C}$ (see Fig. 14), the floor slab panels deformed less double curvature, due to the significant deflections of protected secondary beams. Hence, the tensile membrane actions within the floor slabs were reduced considerably.

For the Natural Fire case, similar behaviours of protected secondary beams and floor slabs were noticed (see Fig. 13). When the temperatures of the protected secondary beams approached around $150^{\circ} \mathrm{C}$, the related temperatures of unprotected secondary beams were nearly $700^{\circ} \mathrm{C}$. At this point, the strength and stiffness of unprotected secondary beams began to reduce. Within the fire compartment, alternative load paths were adopted to transfer the load. Therefore, with the increasing of temperatures, the deflections at position $\mathrm{P} 2$ is higher than that of position P1.

It is clear from the above analysis that the behaviour of connections positioned at the perimeter of slab panels has a significant influence on the formation of tensile membrane action. In this research, the load factor of the vertical shear of connections between protected secondary beams and columns is 0.3 . However, in this case the connections still failed, due to loads transferred from unprotected beams to the protected beams as the fire developed. The failure of connections connected to the protected beams reduced the vertical support to the slab panels. Hence, the positive influences of tensile membrane action within the floor slab panel were significant reduced. Therefore, for the structural fire engineering design, if the designers want to leverage the benefits of tensile membrane action on the performance of composite floors in fire, the vertical shear capacity of the connections between protected secondary beams and columns needs to be significant increased compared to normal design. 
This ensures that the connections have sufficient resistance to the larger loads, due to the load transfer from unprotected beams to the protected beams under fire conditions.

\subsection{Influence of different slab reinforcement}

Three different steel meshes (A142, A252 and A393) were taken into account in this research, to demonstrate the effect of slab reinforcement on the structural behaviour under fire conditions. The predicted deflections at position P3 and P4 under ISO834 Fire condition are illustrated in Figs 15 and 16. It can be observed that the impact of different slab reinforcement is negligible, up to $500{ }^{\circ} \mathrm{C}$. But beyond $500{ }^{\circ} \mathrm{C}$, the differences between the three steel meshes become more obvious. When the steel beams lose strength and stiffness at high temperatures, the concrete slab plays a more important role in supporting the loads. The ultimate load-carrying capacity of concrete slabs largely depends on the reinforcement area and strength. Therefore, at high temperatures, the impact of steel reinforcement becomes more significant.

Figs 17 and 18 show the predicted deflections at the centre of the panels P3 and P4, when modelling using the Natural Fire condition. The temperatures of the horizontal axis refer to the temperatures of the unprotected secondary beam. As mentioned in Section 2, the effect of the cooling phase in a natural fire on the behaviours of steel beams, floor slabs, connections and their interactions are fully considered in the model. In this model the residue strains of steel beam and reinforcement of concrete slab are considered. It is clearly shown in Figs 17 and 18 that the recovery rates of concrete slab's deflection for three different meshes are very similar. This confirms that the unprotected secondary beams play a main role on the recovery of concrete slabs' deflection during the cooling phase of a natural fire. The large residue deflection of concrete slab with A142 mesh is due to the large residue strains existed within the unprotected secondary beam and steel reinforcement of concrete slab during the heating phase of the fire. As can be seen from Figs 17 and 18, it is obvious that the deflection of slab panel would reduce, if using a higher steel mesh under fire conditions. As explained above, this is because the concrete slab plays a more important role in supporting the loads, when the strength and stiffness of steel beams decrease rapidly at high temperatures.

For layered slab element model used in this study, there are 9 Gauss integration points used for each slab element. All stresses are calculated at each Gauss point along the thickness of each slab element. Hence, there are two principal membrane tractions (vectors, forces per unit width) at each Gauss point. They are calculated from two principal stresses along the 
thickness of the slab at that Gauss point. Each slab element has 18 principal membrane tractions (vectors) distributed over a slab element. The magnitude of the tractions (vectors) is a quantitative indication of the membrane actions within the slab floor considered. Fig. 19 shows the distribution of principal membrane tractions (vectors) at 9 Gauss points of each slab element under ISO Fire condition. This vector plot was obtained when the temperature was $1008{ }^{\circ} \mathrm{C}$, with A142 slab reinforcement. The length of the vector is proportional to its magnitude. The thick (blue) line refers to compression, while the thin (red) line relates to tension. It can be clearly seen that the tensile membrane action occur within the centre of each slab panel, while a compressive ring forms around the perimeter of each slab panel. Fig. 20 shows the distribution of principal membrane tractions (vectors), with A393 slab reinforcement at $1008{ }^{\circ} \mathrm{C}$. Compared to the A142 steel mesh, the tensile membrane action of slab panel with the A393 steel mesh is more significant.

\subsection{Influence of vertical support of protected beams}

In order to quantitatively illustrate the effect of membrane action of the concrete floor slabs, both geometrically linear and nonlinear slab elements with A393 steel mesh were used to model the proposed composite frame under ISO Fire condition. When using the geometrically linear slab element to represent the concrete floor slabs for analysing the performance of fire compartment, only the normal bending of slab elements were taken into consideration. The effects of membrane actions within the floor slabs were totally ignored. For the modelling using the geometrically nonlinear slab elements, the membrane actions within the floor slabs were fully considered. Figs 21 and 22 give the comparison results of the floor slabs' deflections at position P3 and P4, for using geometrically linear and nonlinear procedures. It can also be clearly seen that in this case the influence of membrane action is very significant. When the temperature of the unprotected secondary beam reached about $1000{ }^{0} \mathrm{C}$, the deflection at the centre of the slab panel which considered the effect of tensile membrane action was only half of that without considering membrane action. When the temperature of the unprotected secondary beam is less than $750^{\circ} \mathrm{C}$, the deflection of the floor slabs is below $250 \mathrm{~mm}$; hence, there was very little influence of tensile membrane action within the floor slabs. When the temperature increased further, the unprotected secondary steel beams lose its strength and stiffness significantly. Then, the loads within the floor slabs are mainly carried by the floor slabs, and the tensile membrane action within the floor slabs will play an important role in enhancing the load capacity of the floor slabs. 
In order to quantitatively assess the influence of the vertical support provided by the protected beams along the edges of slab panel on the membrane actions of the floor slabs, the case with A142 mesh under ISO fire condition was reanalysed with all protected beams fixed vertically. This means that all protected beams along the column grid lines have no vertical deformation, and the slab panels were fully vertically supported along the edges.

Figs 23 to 25 demonstrate the comparisons of the displacements at position P3, P4, and P5, with fixed and non-fixed vertical support on protected steel beams. For the non-fixed case the protected steel beams were free to deflect vertically as the normal situation. From the comparison results, it can be noticed that the discrepancy between these two cases increases after the temperature of unprotected beams reaches $700^{\circ} \mathrm{C}$. Beyond this temperature, the unprotected secondary beam loses strength progressively, leading to the loads above the slab panel being redistributed to the protected edge beams along the slab panels. Fig. 14 shows the deflection profiles of slab at $1008{ }^{0} \mathrm{C}$ for the normal case, in which the protected secondary beams were free to deform vertically. It is evident that the protected secondary beams were vertically deflected significantly due to the increased loads resulted from the high temperature of unprotected beams. For the case in which all protected beams were fixed vertically, the protected secondary beams have no vertical deflections at all. Compared these two cases, the slab panels within the fire compartments were deformed less double curvature in the normal case. Hence, the tensile membrane action of the slab panel was considerably reduced. In comparison for the case with fixed support on the protected beams, the slab panel was fully vertically supported along the edges of the slab panel. Therefore, the slab panel was forced to deform double curvature hence the tensile membrane action within the slab panel was fully maximized. In this situation, the load capacity of the slab panel considered was significantly enhanced due to the tensile membrane action.

The investigation reported above demonstrated that the influence of the vertical support condition on the tensile membrane action of floor slabs is significant. It is important for fire structural engineering designers account for this issue, when they attempt to utilise the tensile membrane action of floor slabs for as part of simpler design methods.

\section{Design recommendations}

The numerical studies described above show that the provision of vertical support along the slab panel has a significant impact in the formation of tensile membrane action within the floor slabs under fire conditions. At a higher temperature, the loads within the floor slabs of 
fire compartment (initially supported by unprotected secondary beams in the fire compartment) will be redistributed into protected beams along the column grid lines. This large load will cause the protected secondary beams to deform significantly. Also, the high load will result in vertical shear failure of the connections which connect protected secondary beams to the columns. All of this will significantly undermine the vertical support conditions on floor slab panels within the fire compartment. In return, the benefit of tensile membrane action for enhancing the load carry capacity of the floor slab panels, as initial assumed in the performance-based design, could be considerable reduced.

Therefore, the load-carrying capacities of connections between protected beams and columns need to be adequately designed to resist larger vertical shear forces compared to normal design. The primary requirements for effective use of the tensile membrane action of the floor slabs is to make sure that the strong vertical supports along the edges of floor slab panels are maintained during the required fire resistance period. Floor slab panels are forced to deform, as the double curvature shape. If the protected edge beams undergo excessive deformation, the floor slab panels may convert into a single-curvature deformation, which will reduce the benefit of tensile membrane action significantly. Therefore, the protected beams along the perimeter of the slab panels should be designed carefully, to provide sufficient vertical support during fire. A higher reinforcement ratio for floor slabs may also be used to enhance the positive influence of the tensile membrane action to improve the fire resistance of the composite floor system.

The main aim of this study is to (first time) present an initial large-scale numerical investigation to quantitatively understand the effects of protected beams and their connections on the fire resistance of composite buildings. Through this research the main design recommendation is: in order to safely use the benefits of the tensile membrane action of concrete floor slab on the fire resistance design of composite buildings, a performance based design procedure by using large-scale computer modelling is essential.

Designers need to make sure that the protected beams and their connections along the perimeter of the slab panels have sufficient stiffness and strength to provide vertical support during required fire resistance time. The design of protected secondary beams and their connections need to be done case by case based on the modelling results. From this study it is clear that the influence of tensile membrane actions on the behaviour of composite floor varies during fire. It is depended on the deformed profile of floor slabs which are complexly 
related to $3 \mathrm{D}$ structural system and their interactions. Hence, in the design it is unsafe to adopt simplified approach for utilising tensile membrane action to enhance fire resistance of composite building. For proposing generalised design recommendations, further researches are needed to carry out more comprehensive numerical analysis for different structural configurations, levels of strength and rigidity of protected beams and their connections under different fire conditions.

\section{Conclusions}

In this paper, a comprehensive study was conducted on a generic three dimensional 45m x 45m composite building, with realistic loading conditions and structural layout, under different fire conditions. A series of analyses has been carried out using different support conditions, on slab panels and slab reinforcement details. In this research, the end-plate connections were used to connect primary beams to columns. The partial end-plate connections were adopted to connect secondary beams to columns, and primary beams to secondary beams, respectively. These two types of connections were modelled using the simplified connection models developed by the authors. The research conducted here systematically investigated the impact of the connections for protected beams on the tensile membrane actions of supported floor slabs, in which the failure of the connections due to axial tension, vertical shear, or bending was considered. The influence of the vertical deflections of protected beams on the tensile membrane action of the floor slabs has been analysed in detail. The effects of different reinforcement details of the floor slabs, on the performance of a composite floor under different fire conditions, were also evaluated.

Based on the results of this investigation, the following conclusions can be drawn:

(1) At high temperatures, the strength and stiffness of unprotected steel beams reduce rapidly. The loads above the fire compartment are largely carried by the concrete floor slabs. Hence, the impact of steel reinforcement on the behaviour of floor slabs becomes more significant.

(2) At higher temperatures, the loads within the floor slabs of fire compartment, initially supported by unprotected secondary beams, are redistributed into protected beams along the column grid lines. This large load causes the protected secondary beams to deform significantly. 
(3) The high loads result in vertical shear failure of the connections, which connect protected secondary beams to the columns. All of this will significantly undermine the vertical support conditions on floor slab panels within the fire compartment.

(4) Once the connections of protected beams fail, the vertical support for the slab panel would reduce. The floor slabs within the fire compartments would deform less double curvature, causing significant reduction of tensile membrane action within the floor slabs.

(5) Therefore, in real performance-based fire resistance design of steel framed composite buildings, the influence of connections needs to be considered carefully. This is in order to maximise the benefit of tensile membrane action.

(6) The designers should design adequate strength and stiffness into protected secondary beams and connections. The primary requirements for tensile membrane action of the floor slabs to be effective used, is to make sure that the strong vertical supports along the edges of floor slab panes are maintained during the required fire resistance period.

\section{Acknowledgement}

We would like to thank Brunel University London for funding this $\mathrm{PhD}$ research.

\section{References}

[1] C.G. Bailey, T. Lennon, D.B. Moore, The behaviour of full-scale steel-framed buildings subjected to compartment fires, StructEng. 77 (1999) 15-21.

[2] Y.C. Wang, Performance of steel-concrete composite structures in fire, Prog. Struct. Engng. Mater. 7(2) (2005) 86-102.

[3] A.K. Abu, Behaviour of composite floor systems in fire, $\mathrm{PhD}$ Thesis, University of Sheffield, 2009.

[4] C.G. Bailey, Membrane action of slab/beam composite floor systems in fire, Eng.Struct. 26 (2004) 1691-1703.

[5] L. Lim, A. Buchanan, P. Moss, J.M. Franssen, Numerical modelling of two-way reinforced concrete slabs in fire, Eng.Struct. 26 (2004) 1081-1091.

[6] G.Q. Li, S.X. Guo, H.S. Zhou, Modelling of membrane action in floor slabs subjected to fire, Eng.Struct. 29 (2007) 880-887.

[7] P.J. Moss, R.P. Dhakal, G. Wang, A.H. Buchanana, The fire behaviour of multi-bay, two-way reinforced concrete slabs, Eng.Struct. 30 (2008) 3566-3573.

[8] N.S. Zhang, G.Q. Li, A New Method to analyse the membrane action of composite floor slabs in fire condition, Fire Technology 46(1) (2010) 3-18. 
[9] H.Z. Jahromi, A.G. Vlassis, B.A. Izzuddin, Modelling approaches for robustness assessment of multi-storey steel-composite buildings, Eng.Struct. 51 (2013) 278-294.

[10] P.X. Dat, K.H. Tan, Membrane actions of RC slabs in mitigating progressive collapse of building structures, Eng.Struct. 55 (2013) 107-115.

[11] A.K. Abu, I.W. Burgess, R.J. Plank, Tensile membrane action of thin slabs exposed to thermal gradients, J. Eng. Mechanics 139(11) (2013) 1497-1507.

[12] A. Nadjai, C.G. Bailey, O. Vassart, S. Han, B. Zhao, M. Hawes, J.M. Franssen, I. Simms, Full-scale fire test on a composite floor slab incorporating long span cellular steel beams, StructEng. 89(21) (2011) 18-25.

[13] Z. Huang, I.W. Burgess, R.J. Plank, Fire resistance of composite floors subject to compartment fires, Journal of Constructional Steel Research. 60 ( 2004) 339-360.

[14] M. Gillie, A.S. Usmani and J.M. Rotter, A structural analysis of the first Cardington test, Journal of Constructional Steel Research, 57 (2001) 581-601.

[15] S. Lin, Z. Huang, M. Fan, Analysis of end-plate connections at elevated temperatures, Steel Compos.Struct. 15(1) (2013) 81- 101.

[16] S. Lin, Z. Huang, M. Fan, Modelling partial end-plate connections under fire conditions, J Constr Steel Res. 99 (2014) 18-34.

[17] Z. Huang, I.W. Burgess, R.J. Plank, Modelling membrane action of concrete slabs in composite buildings in fire. Part I: Theoretical development, J. Struct. Eng. 129(8) (2003) 1093-1102.

[18] Z. Huang, I.W. Burgess, R.J. Plank, Modelling membrane action of concrete slabs in composite buildings in fire. Part II: Validations, J. Struct. Eng. 129(8) (2003) 11031112.

[19] Z. Huang, I.W. Burgess, R.J. Plank, Three-dimensional analysis of reinforced concrete beam-column structures in fire, J. Struct. Eng. 135(10) (2009) 1201-1212.

[20] Z. Huang, I.W. Burgess, R.J. Plank, Effective stiffness modelling of composite concrete slabs in fire, Engineering Structures, 22(9), (2000) 1133-1144.

[21] Z. Huang, A connection element for modelling end-plate connections in fire, J Constr Steel Res., 67(5), (2011) 841-853.

[22] L.C. Neves, F. Gomes, Guidelines for a numerical modelling of beam-to-column minor-axis joints, COST C1 Report of W.G. 6-Numerical Simulation, European Commission, Brussels, (1999) 48-60.

[23] L.R.O. Lima, S.A.L. Andrade, P.C.G.S. Vellasco, L.S. Silva, Experimental and mechanical model for predicting the behaviour of minor axis beam-to-column semirigid joints, Int. J. Mechanical Sci. 44 (2002) 1047-1065.

[24] CEN, BS EN 1993-1-8:2005 Eurocode 3: Design of steel structures - Part 1-8: Design of joints. Brussels: European Committee for Standardisation, (2005).

[25] SCI, P358: Joints in steel construction: Simple joints to Eurocode 3. Berkshire: The Steel Construction Institute, (2011).

[26] S. Lin, Development of robust connection models for steel and composite structures in fire, $\mathrm{PhD}$ thesis, Brunel University London, (2014). 
[27] Y. Hu, J.B. Davison, I.W. Burgess, R.J. Plank, Component modelling of flexible endplate connections in fire. Steel Struct. 9 (2009) 1-15.

[28] CEN, BS EN 1993-1-2:2005 Eurocode 3: design of steel structures -Part 1-2: General rules- structural fire design. Brussels: European Committee for Standardisation, (2005).

[29] Z. Huang, A. Platten, J. Roberts, Non-linear finite element model to predict temperature histories within reinforced concrete in fires, Building and Environment 31(2) (1996) 109-118. 


\section{Figure Captions}

Fig. 1 Tensile membrane action within floor slabs

Fig. 2 Division of composite structures into beam, slab elements

Fig. 3 Comparison results of Test EP_20_45_07-09-07 $\left(20^{\circ} \mathrm{C}, \theta=45^{\circ}\right)$ [27]

Fig. 4 Comparison results of Test EP_450_35_11-05-07 $\left(450^{\circ} \mathrm{C}, \theta=35^{\circ}\right)[27]$

Fig. 5 Comparison results of Test EP_650_55_11-07-07 $\left(650^{\circ} \mathrm{C}, \theta=55^{\circ}\right)$ [27]

Fig. 6 Layout of $45 \mathrm{~m} \times 45 \mathrm{~m}$ composite floor

Fig. 7 Configurations of flush end-plate and partial end-plate connections

Fig. 8 Temperature profiles of columns, unprotected and protected beams: (a) ISO Fire; (b) Natural Fire

Fig. 9 Temperature profiles of top, middle, steel mesh and bottom layer of slabs: (a) ISO Fire; (b) Natural Fire

Fig. 10 Predicted vertical shear forces of connections at different positions under ISO Fire: (a) connection shear force versus beam temperatures; (b) connection shear force versus time

Fig. 11 Predicted vertical shear forces of connections at different positions under Natural Fire: (a) connection shear force versus beam temperatures; (b) connection shear force versus time

Fig. 12 Predicted deflections at different positions under ISO Fire: (a) deflection versus beam temperatures; (b) deflection versus time

Fig. 13 Predicted deflections at different positions under Natural Fire: (a) deflection versus beam temperatures; (b) deflection versus time

Fig. 14 Deflection profiles of slab at $1008{ }^{\circ} \mathrm{C}$ (all in $\mathrm{mm}$ )

Fig. 15 Predicted deflections at position P3 under ISO Fire using different steel meshes

Fig. 16 Predicted deflections at position P4 under ISO Fire using different steel meshes

Fig. 17 Predicted deflections at position P3 under Natural Fire using different steel meshes:

(a) deflection versus beam temperatures; (b) deflection versus time

Fig. 18 Predicted deflections at position P4 under Natural Fire using different steel meshes:

(a) deflection versus beam temperatures; (b) deflection versus time

Fig. 19 Distribution of principal membrane tractions with A142 mesh at $1008^{\circ} \mathrm{C}$

Fig. 20 Distribution of principal membrane tractions with A393 mesh at $1008^{\circ} \mathrm{C}$ 
Fig. 21 Predicted deflections at position P3 using geometrically linear and non-linear procedure with A393 mesh under ISO Fire condition

Fig. 22 Predicted deflections at position P4 using geometrically linear and non-linear procedure with A393 mesh under ISO Fire condition

Fig. 23 Comparison of predicted deflections at positions P3 subjected to ISO Fire with nonfixed and fixed vertical support on protected steel beams (A142 mesh)

Fig. 24 Comparison of predicted deflections at positions P4 subjected to ISO Fire with non-fixed and fixed vertical support on protected steel beams (A142 mesh)

Fig. 25 Comparison of predicted deflections at positions P5 subjected to ISO Fire with non-fixed and fixed vertical support on protected steel beams (A142 mesh) 


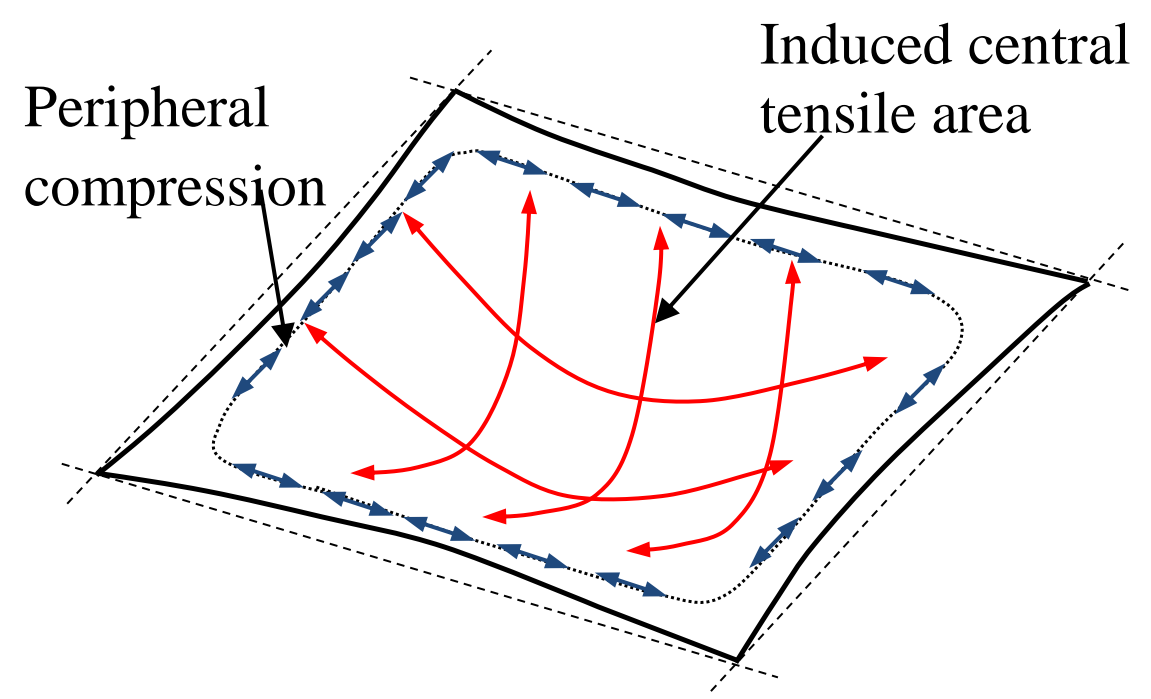

Fig. 1 Tensile membrane action within floor slabs

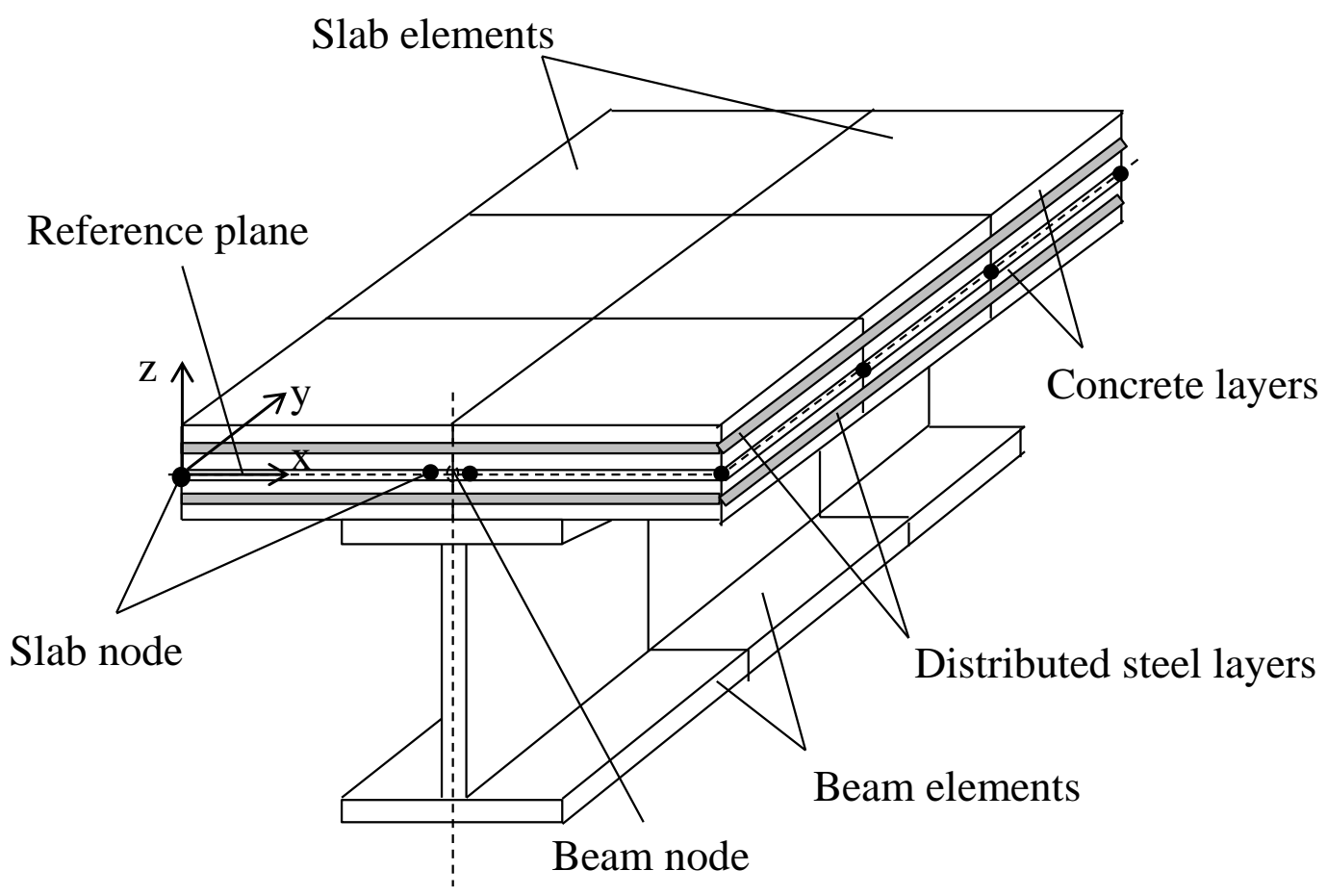

Fig. 2 Division of composite structures into beam, slab elements 


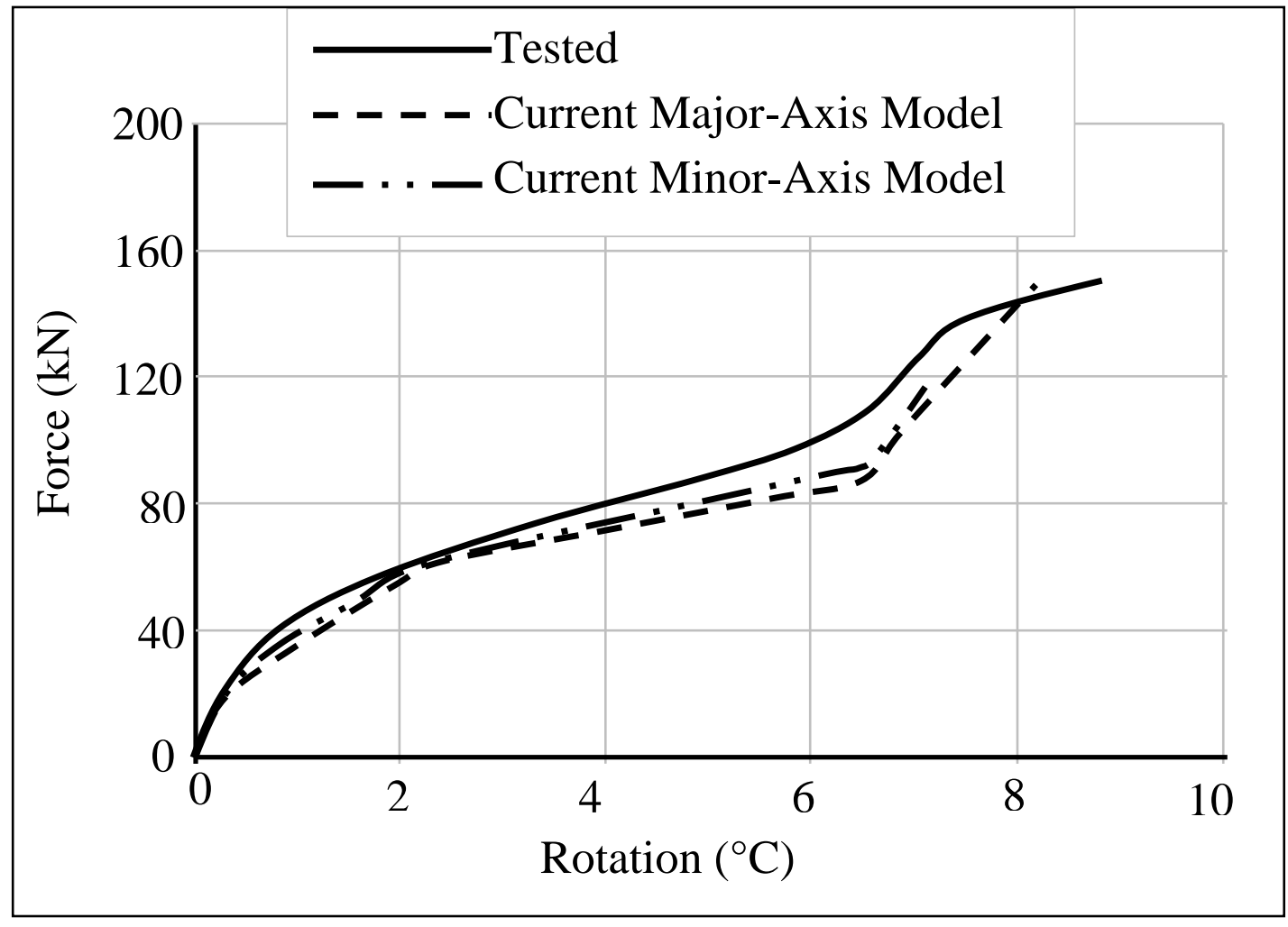

Fig. 3 Comparison results of Test EP_20_45_07-09-07 $\left(20^{\circ} \mathrm{C}, \theta=45^{\circ}\right)$ [27]

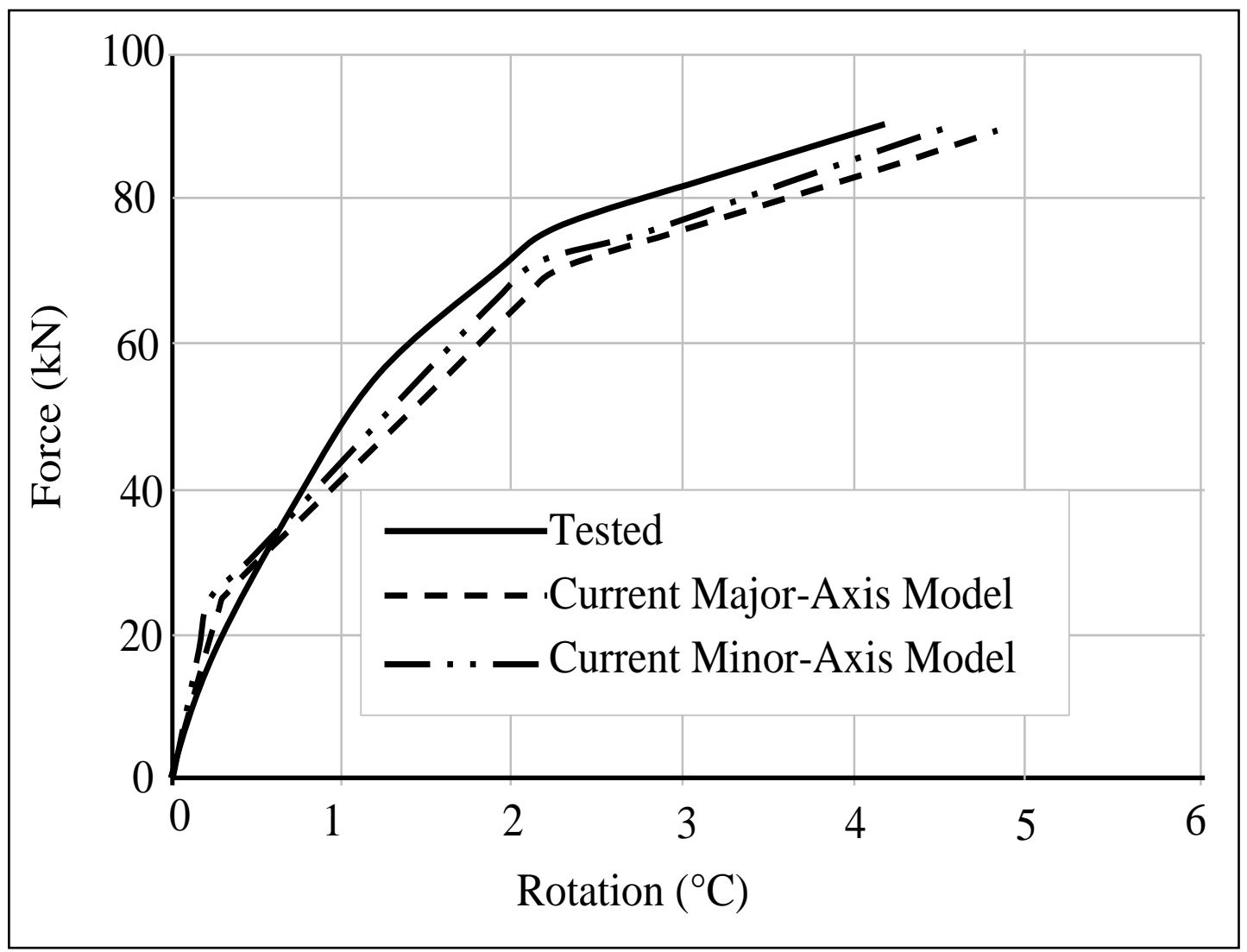

Fig. 4 Comparison results of Test EP_450_35_11-05-07(450 $\left.{ }^{\circ} \mathrm{C}, \theta=35^{\circ}\right)$ [27] 


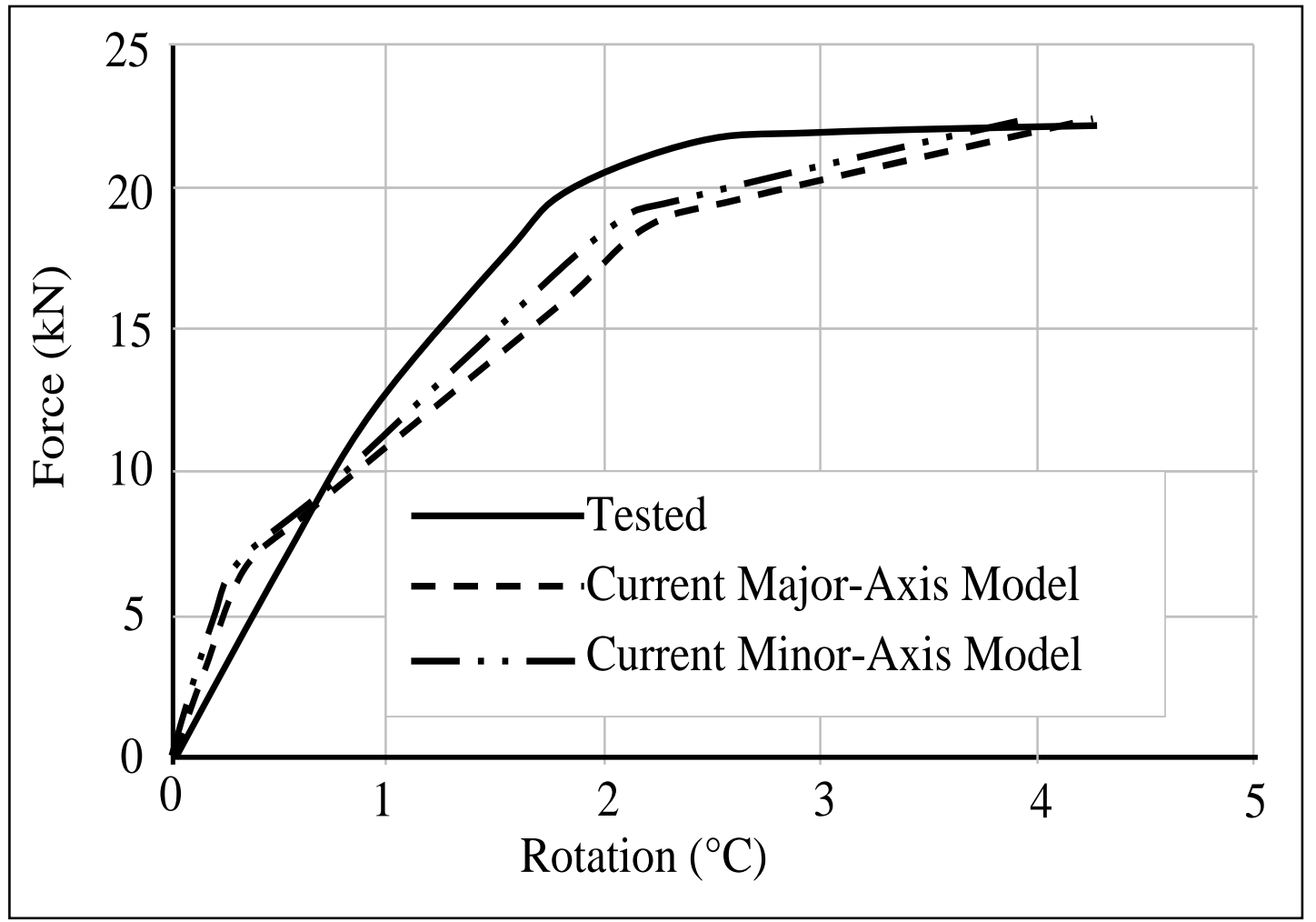

Fig. 5 Comparison results of Test EP_650_55_11-07-07 $\left(650^{\circ} \mathrm{C}, \theta=55^{\circ}\right)$ [27] 


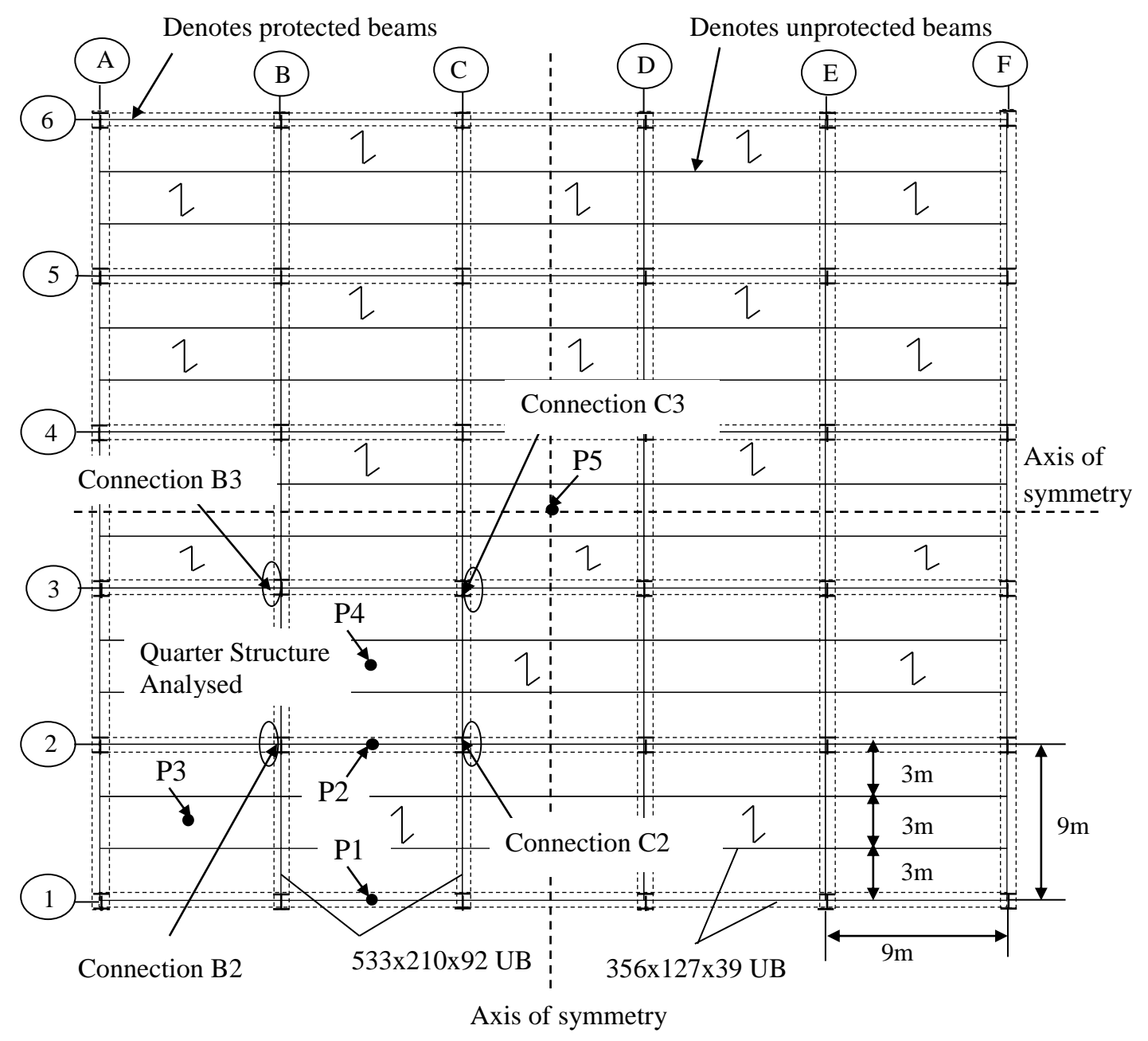

Fig. 6 Layout of $45 \mathrm{~m} \times 45 \mathrm{~m}$ composite floor
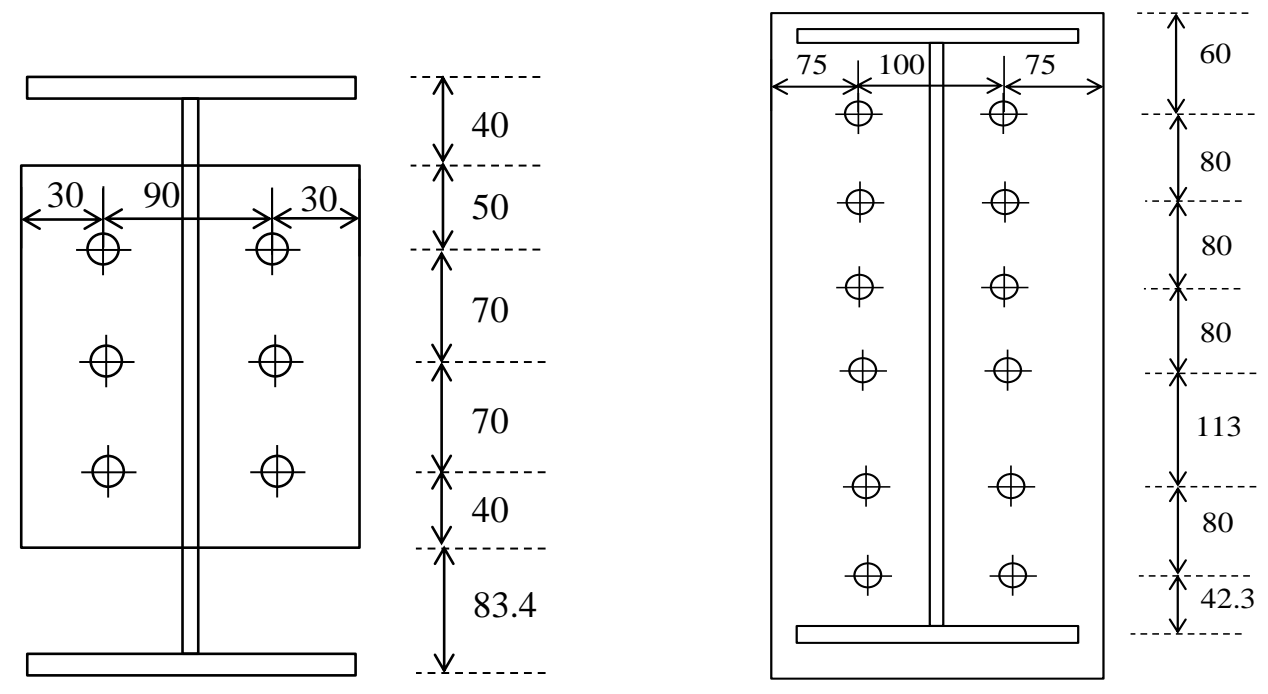

All dimensions in $\mathrm{mm}$

Fig. 7 Configurations of flush end-plate and partial end-plate connections 


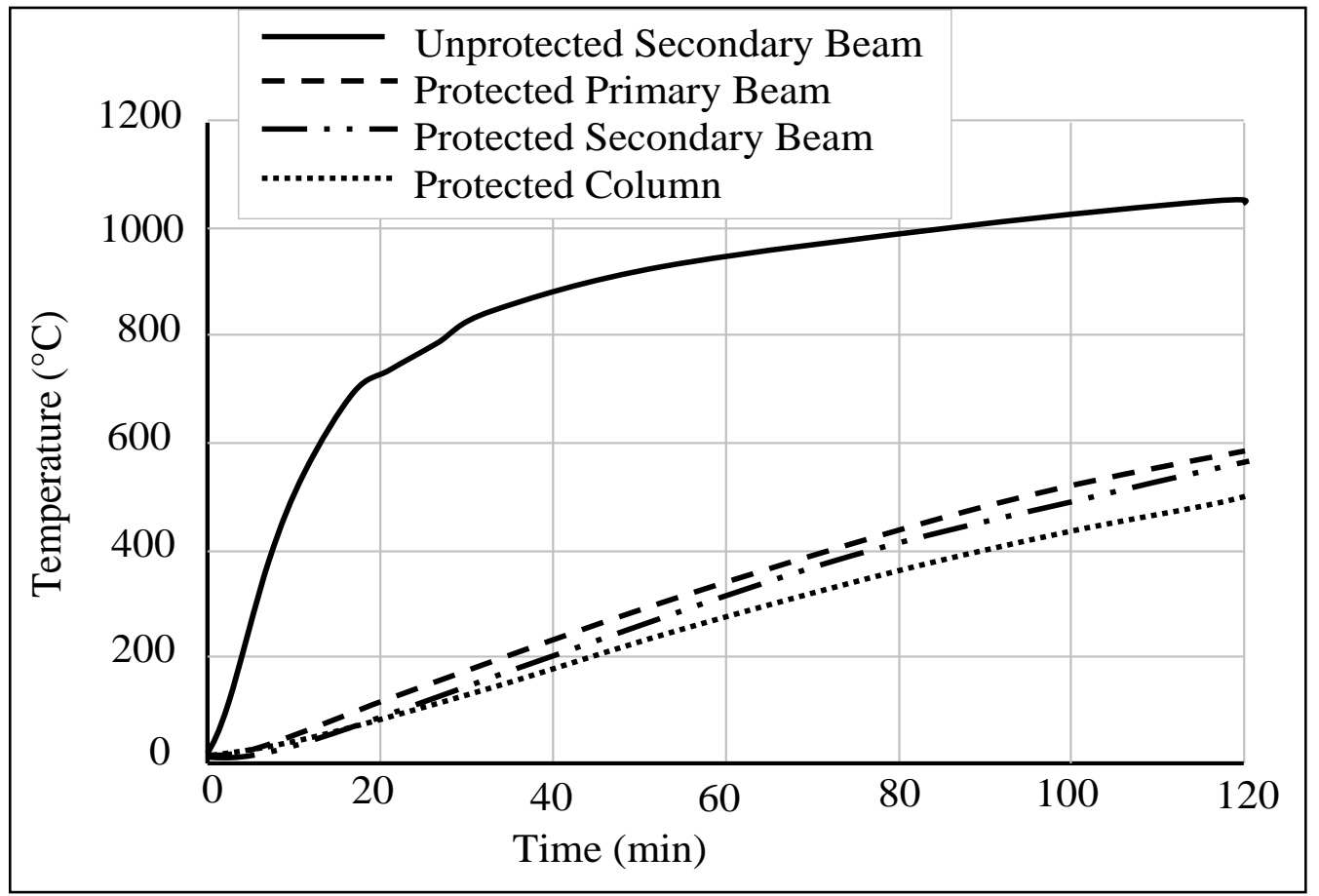

(a)

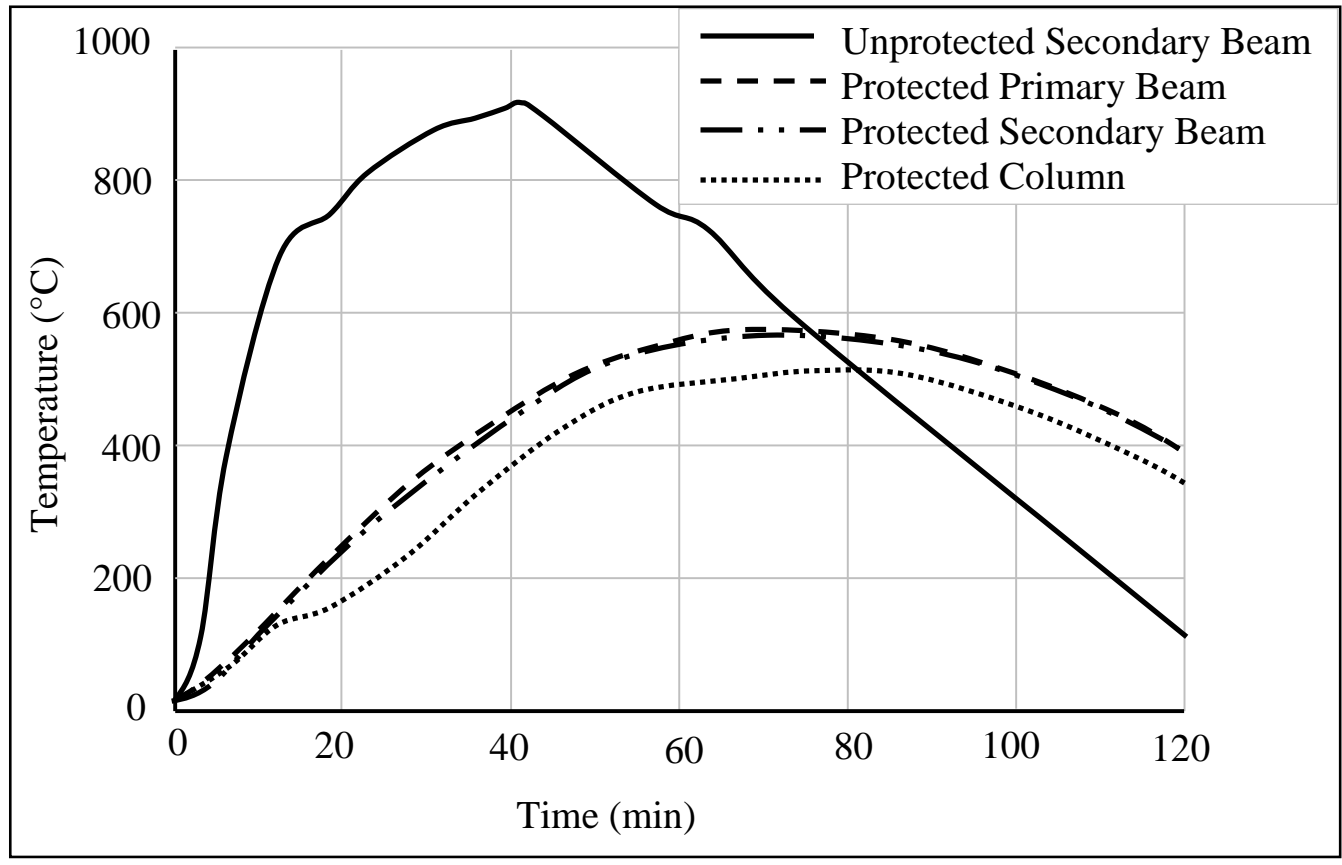

(b)

Fig. 8 Temperature profiles of columns, unprotected and protected beams: (a) ISO Fire; (b) Natural Fire 


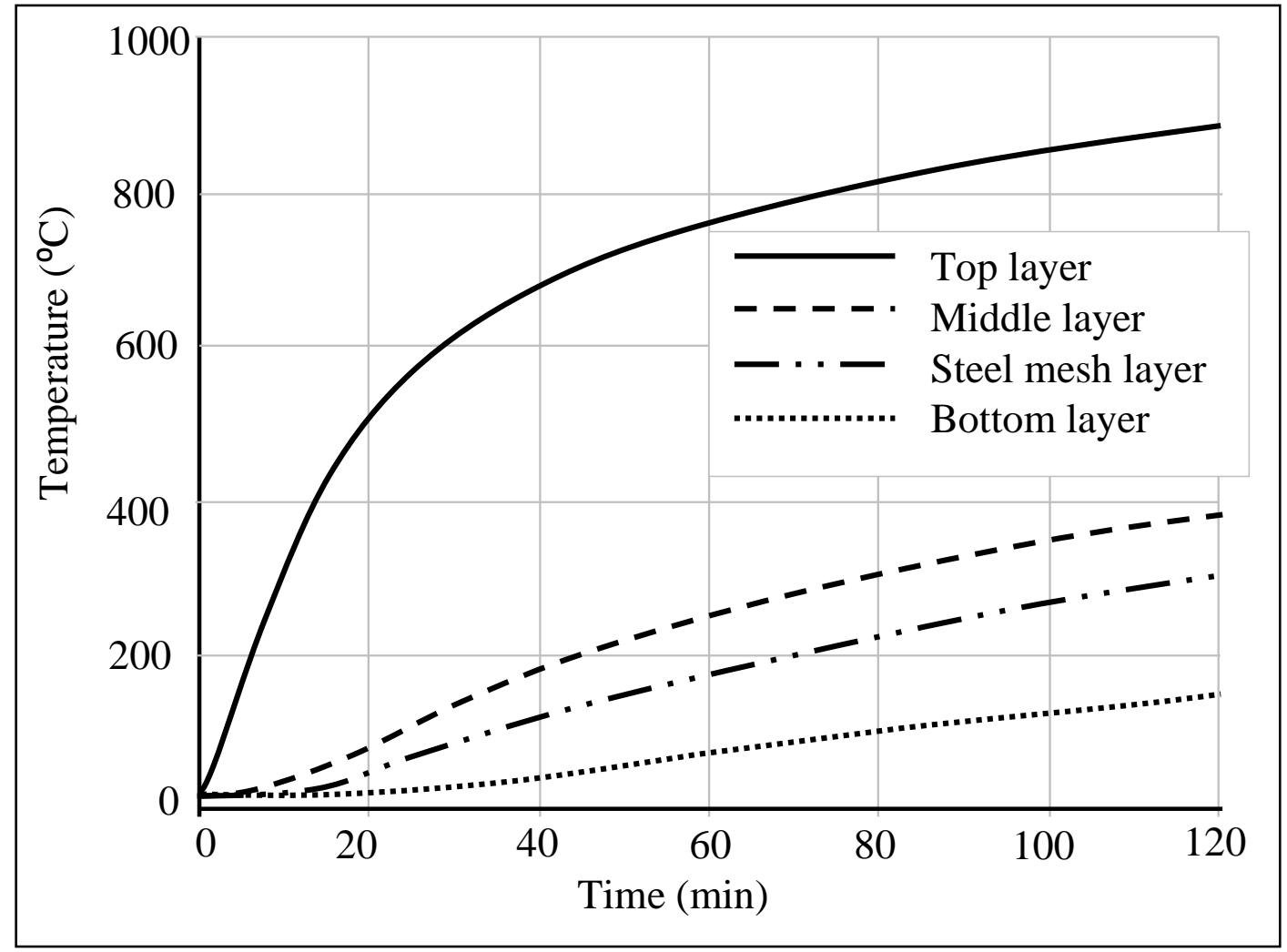

(a)

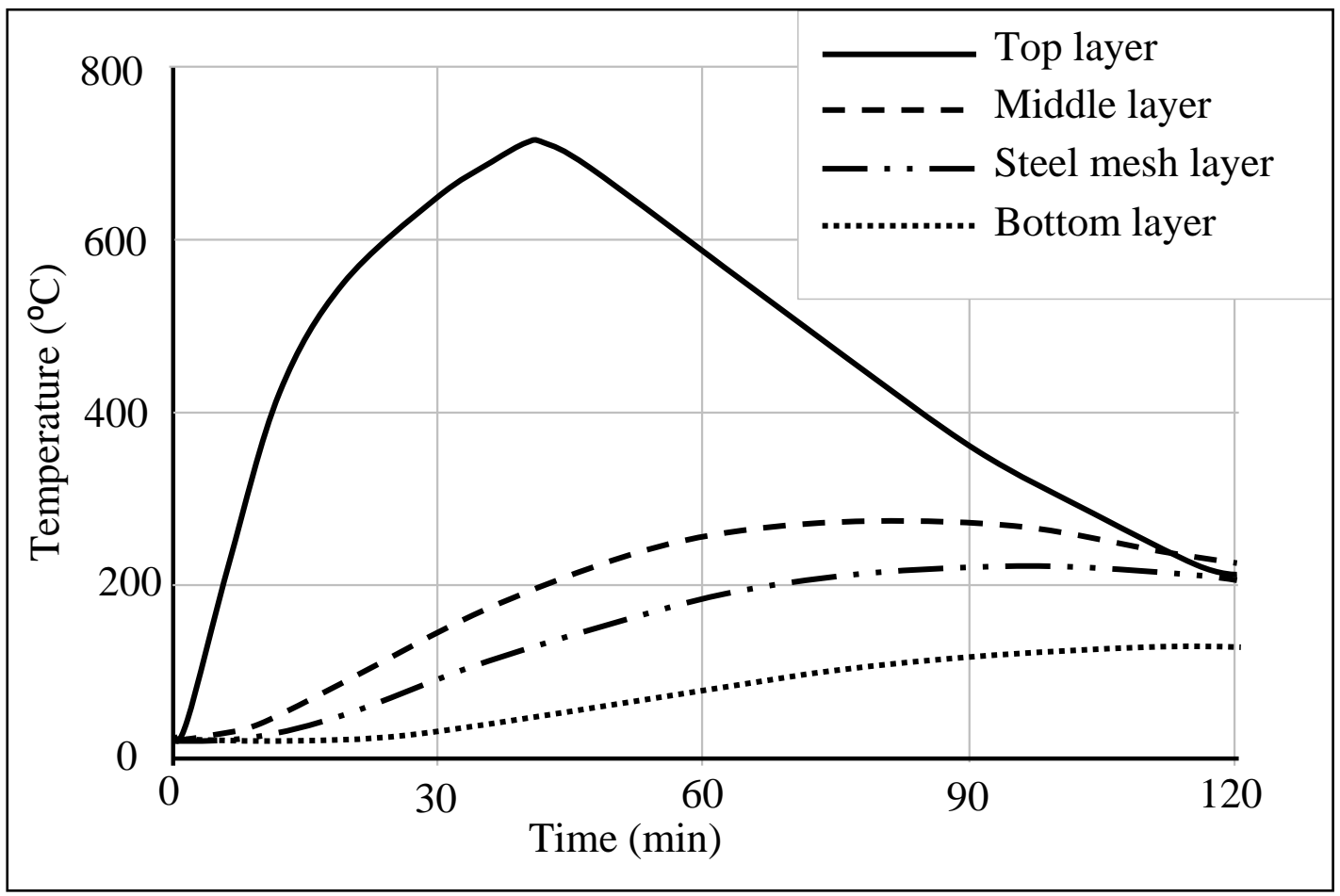

(b)

Fig. 9 Temperature profiles of top, middle, steel mesh and bottom layer of slabs: (a) ISO Fire;

(b) Natural Fire 


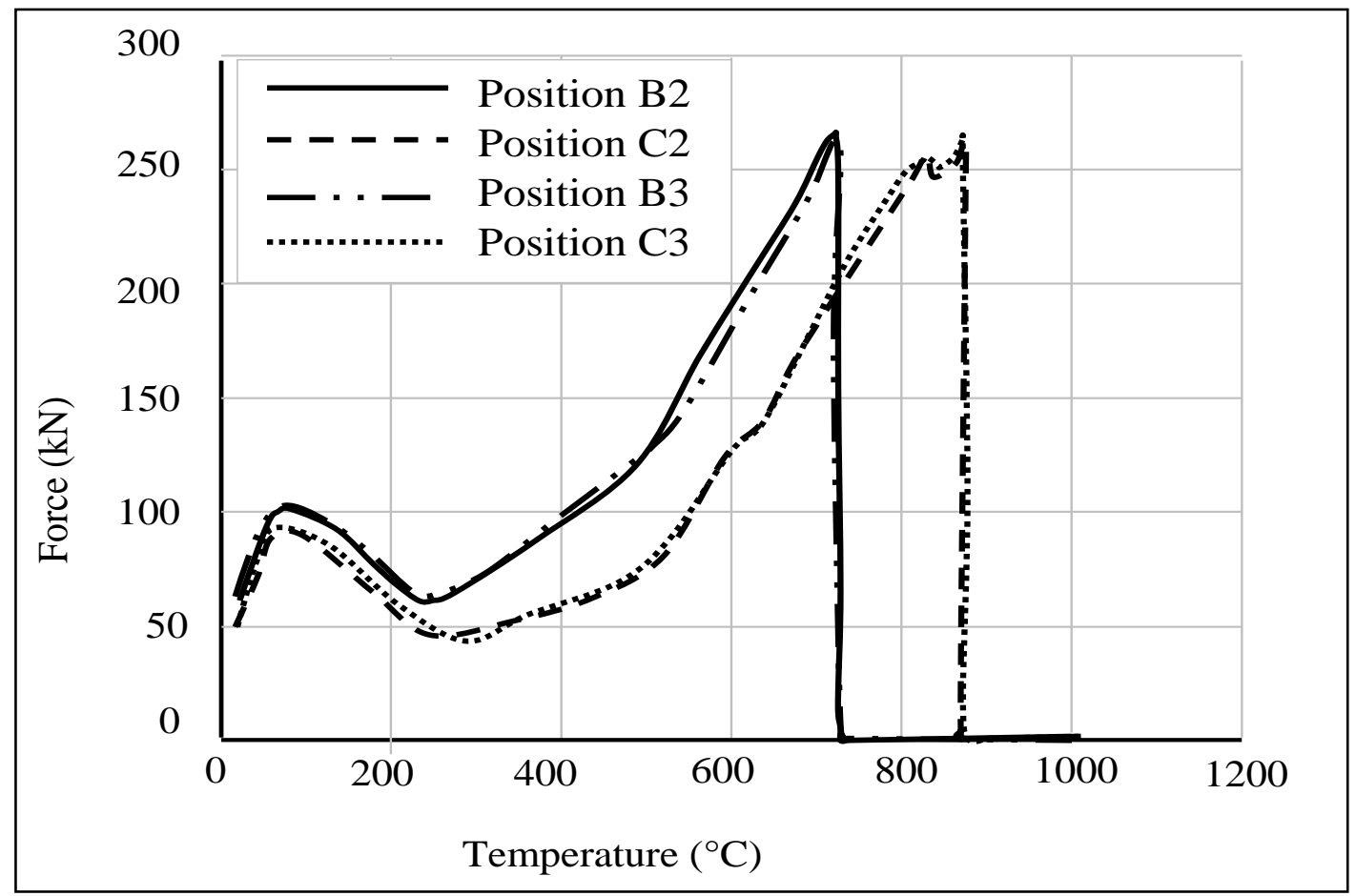

(a)

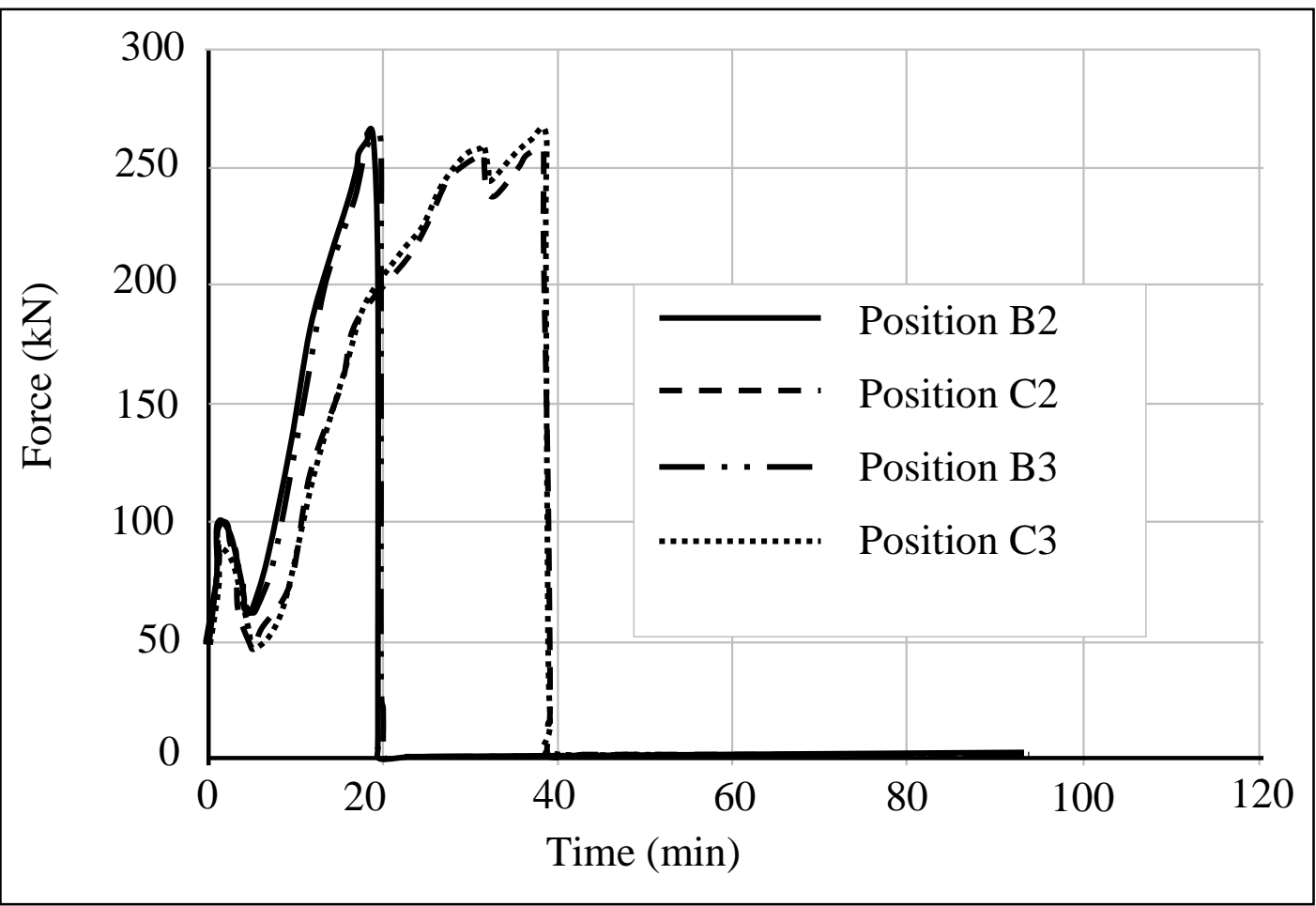

(b)

Fig. 10 Predicted vertical shear forces of connections at different positions under ISO Fire: (a) connection shear force versus beam temperatures; (b) connection shear force versus time 


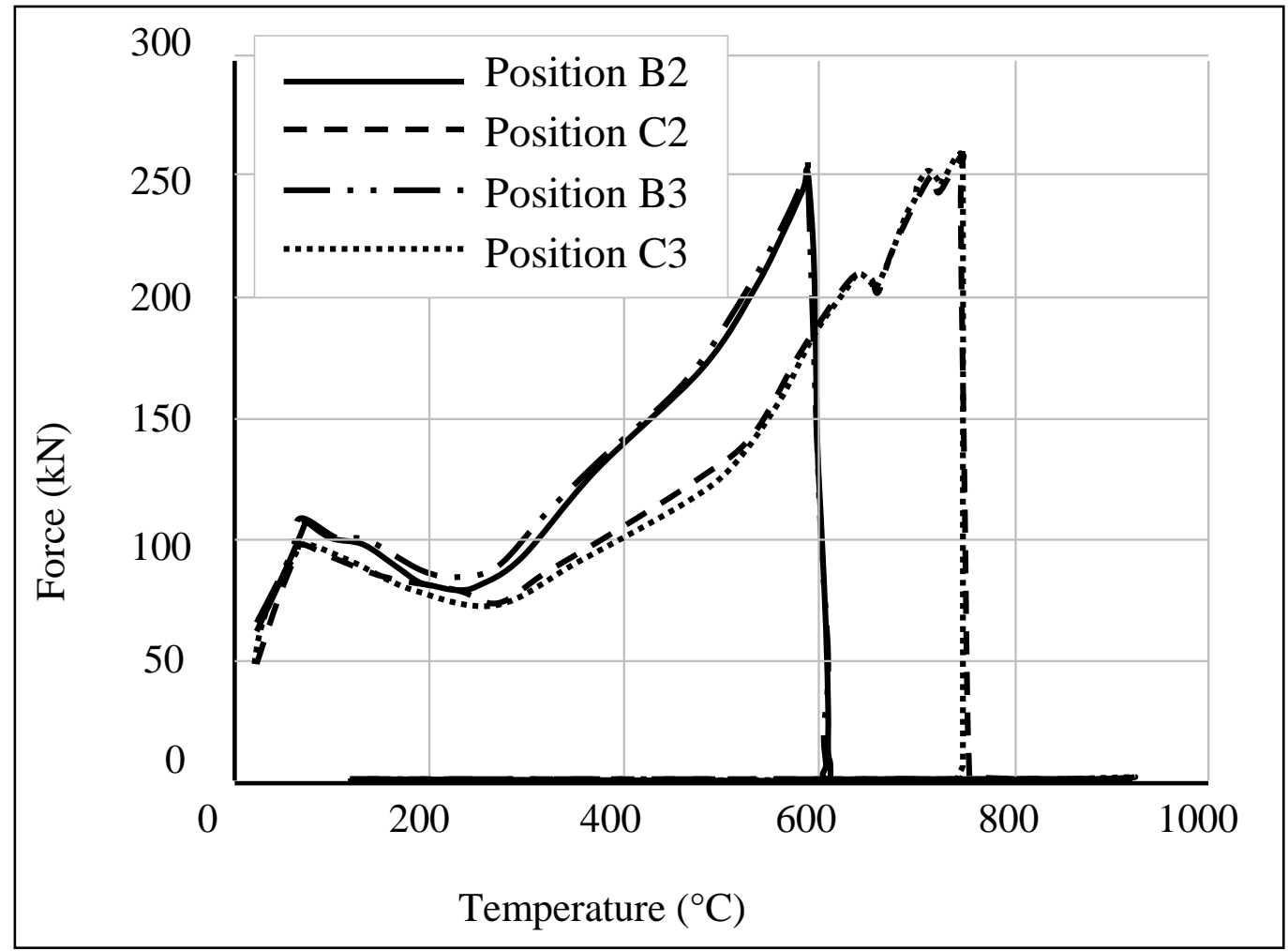

(a)

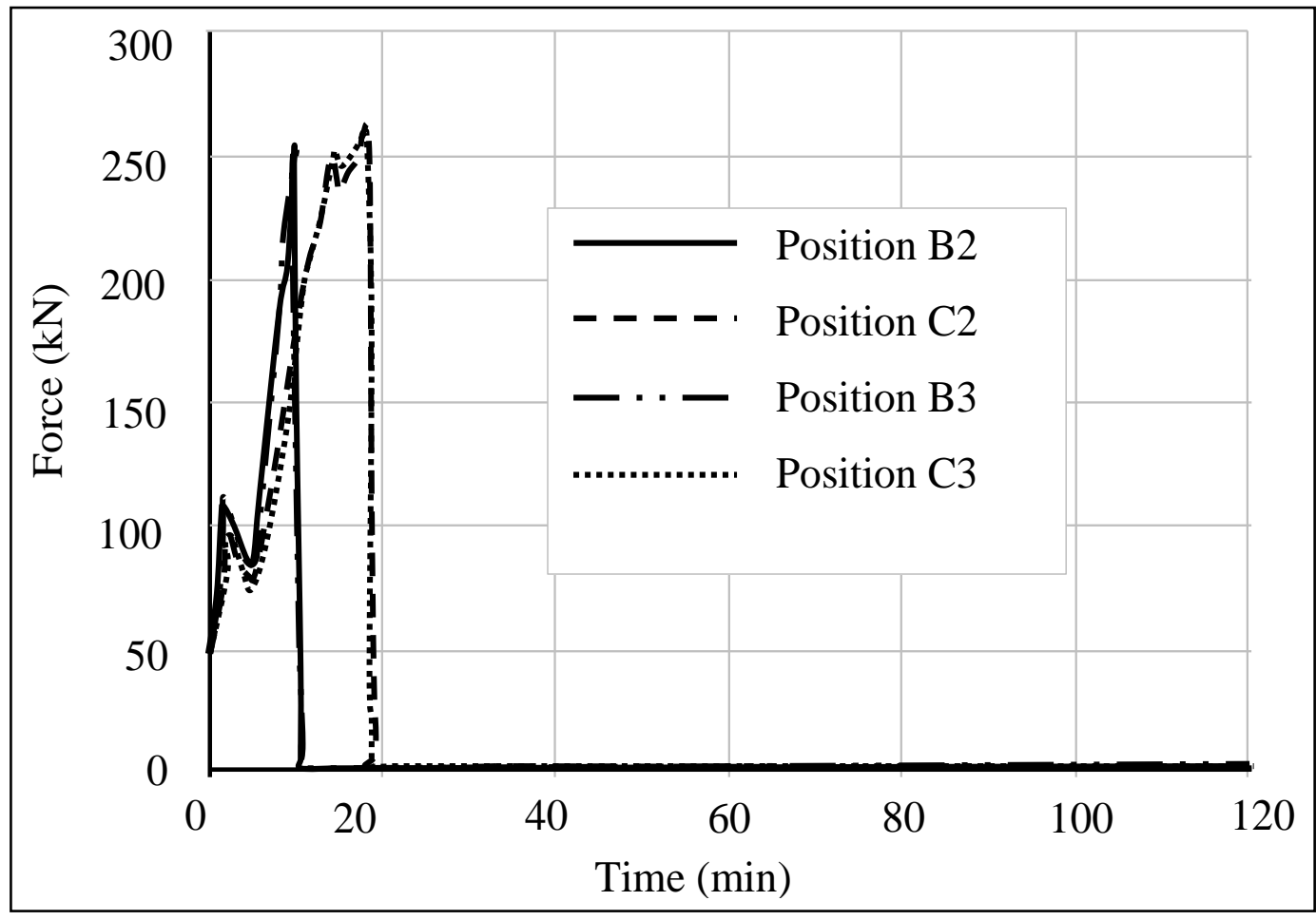

(b)

Fig. 11 Predicted vertical shear forces of connections at different positions under Natural Fire: (a) connection shear force versus beam temperatures; (b) connection shear force versus time 


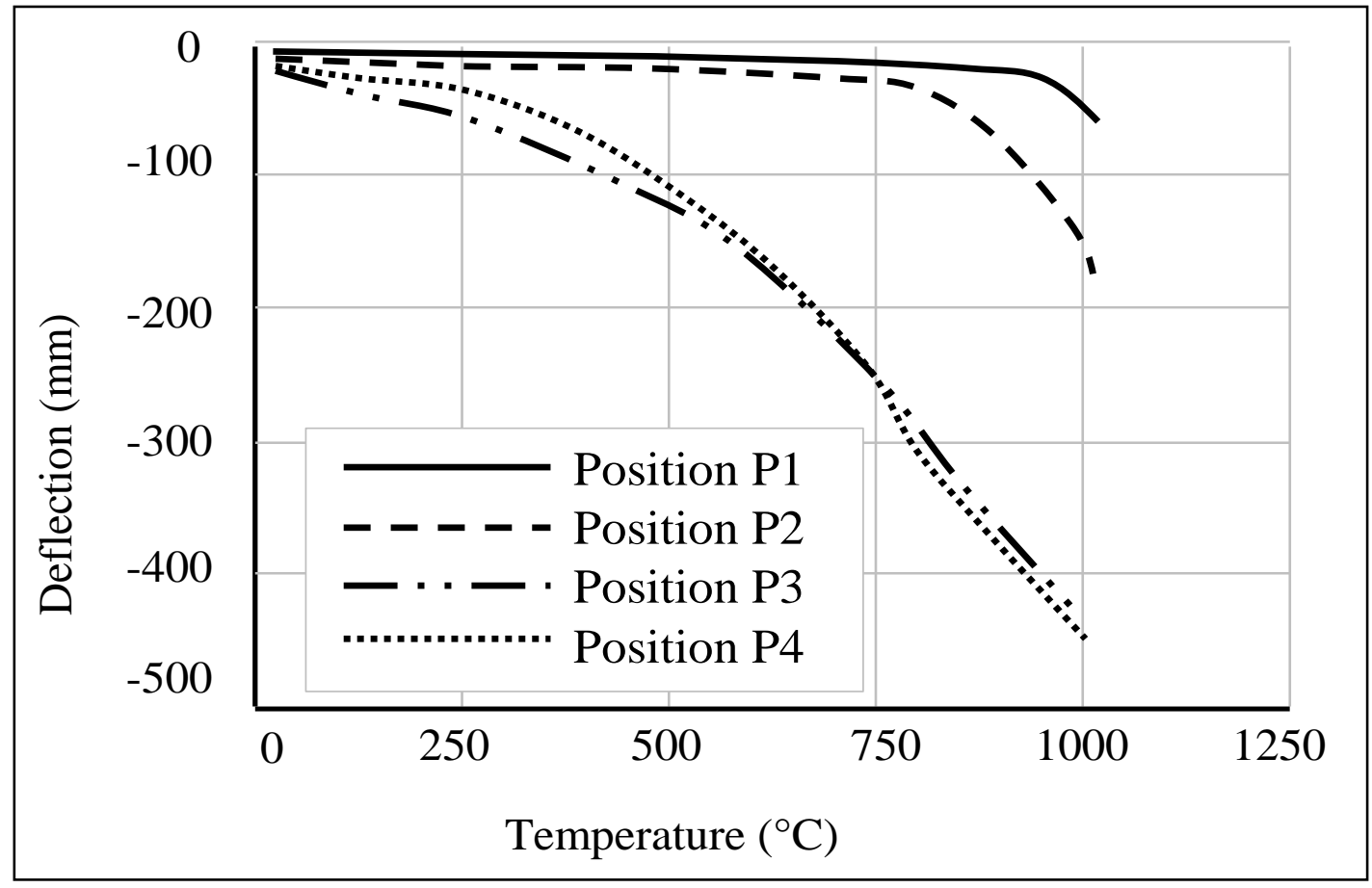

(a)

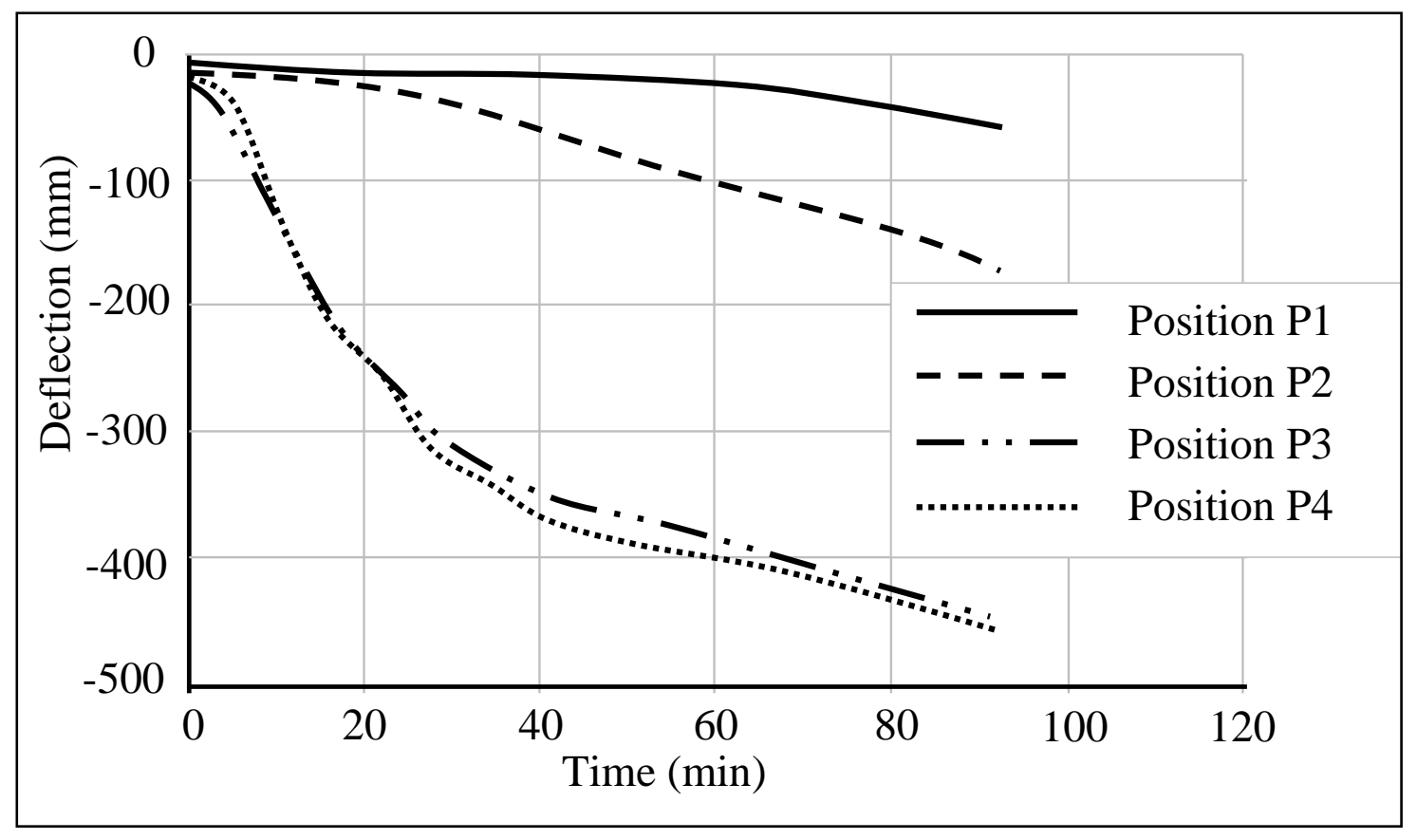

(b)

Fig. 12 Predicted deflections at different positions under ISO Fire: (a) deflection versus beam temperatures; (b) deflection versus time 


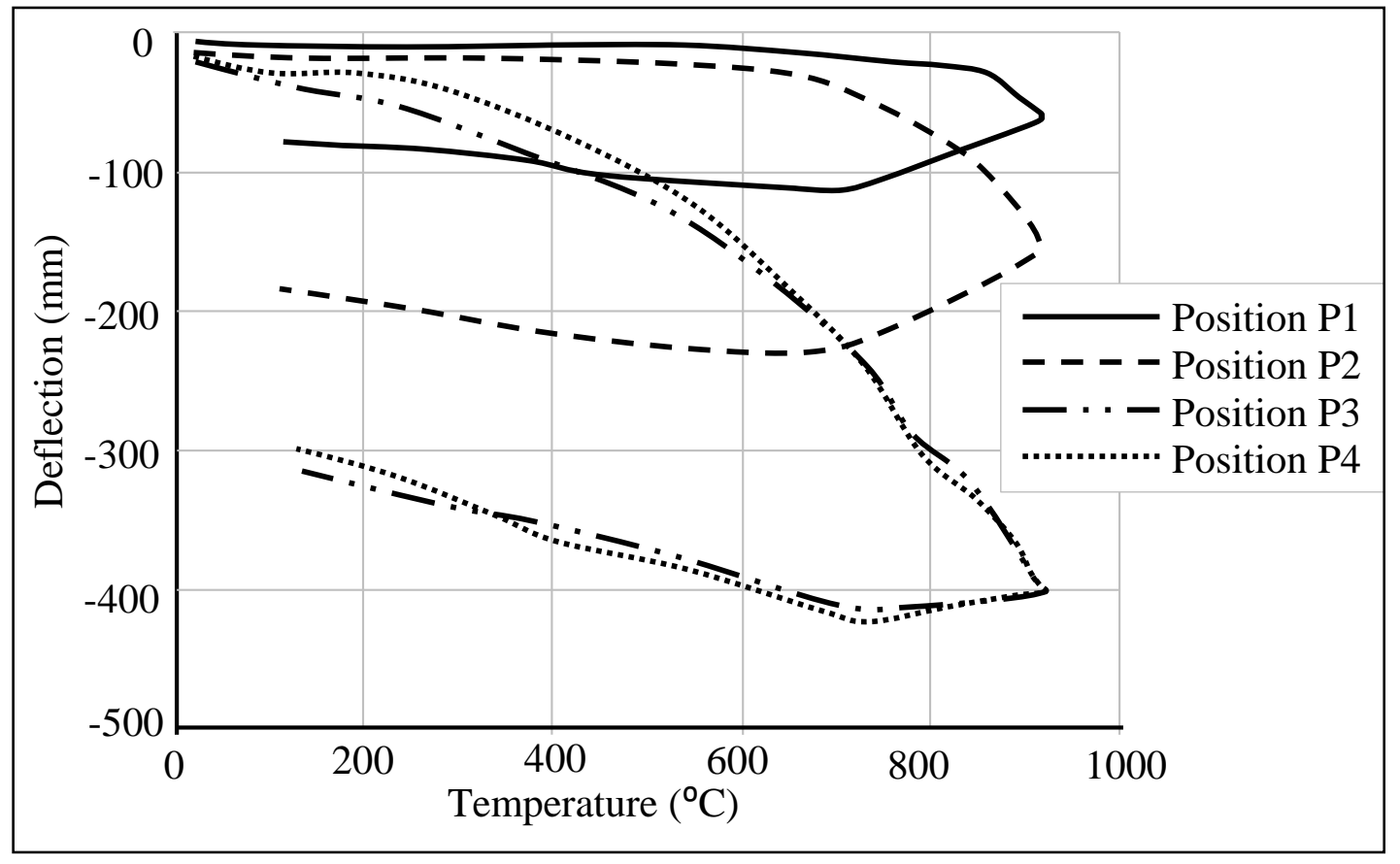

(a)

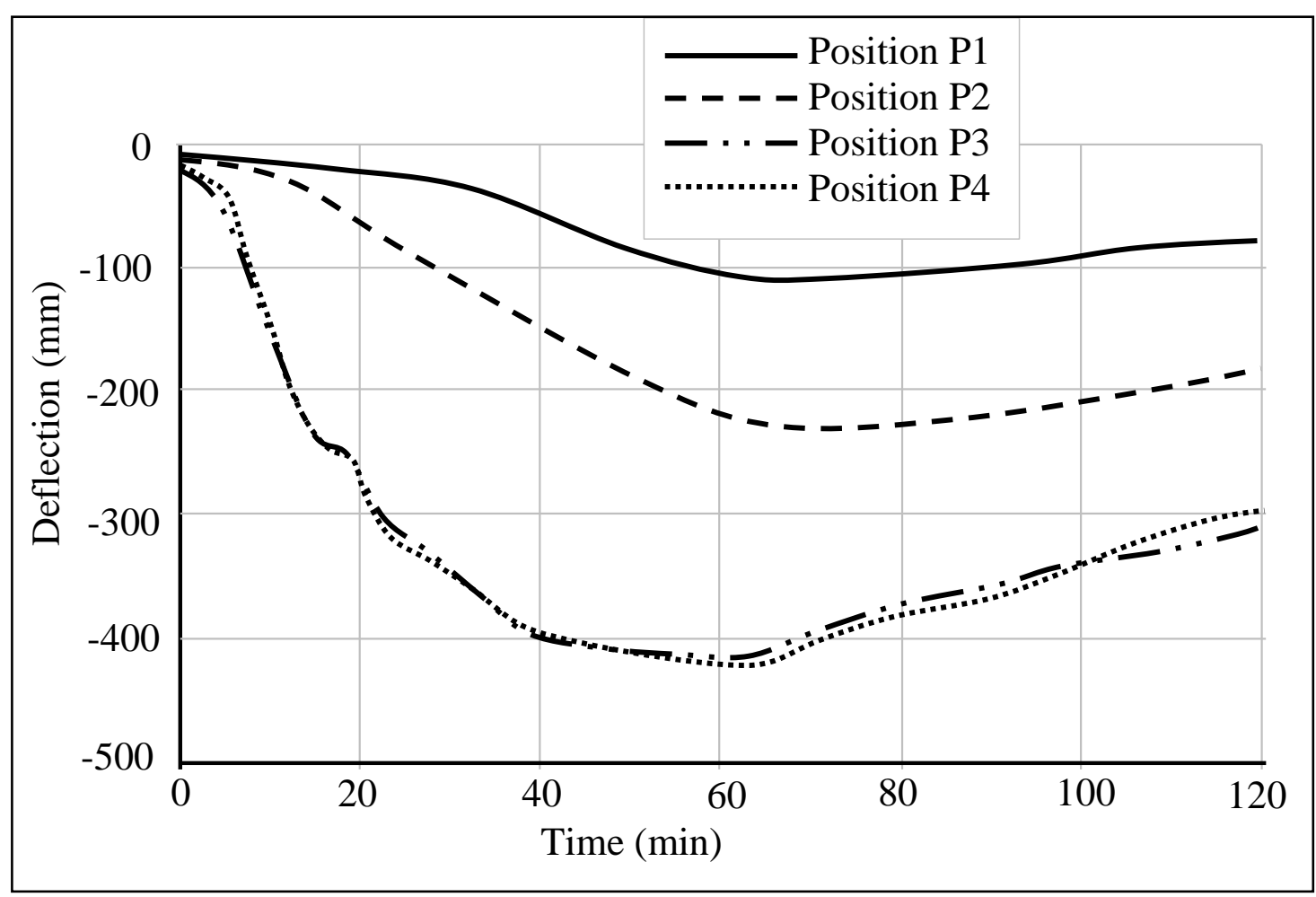

(b)

Fig. 13 Predicted deflections at different positions under Natural Fire: (a) deflection versus beam temperatures; (b) deflection versus time 


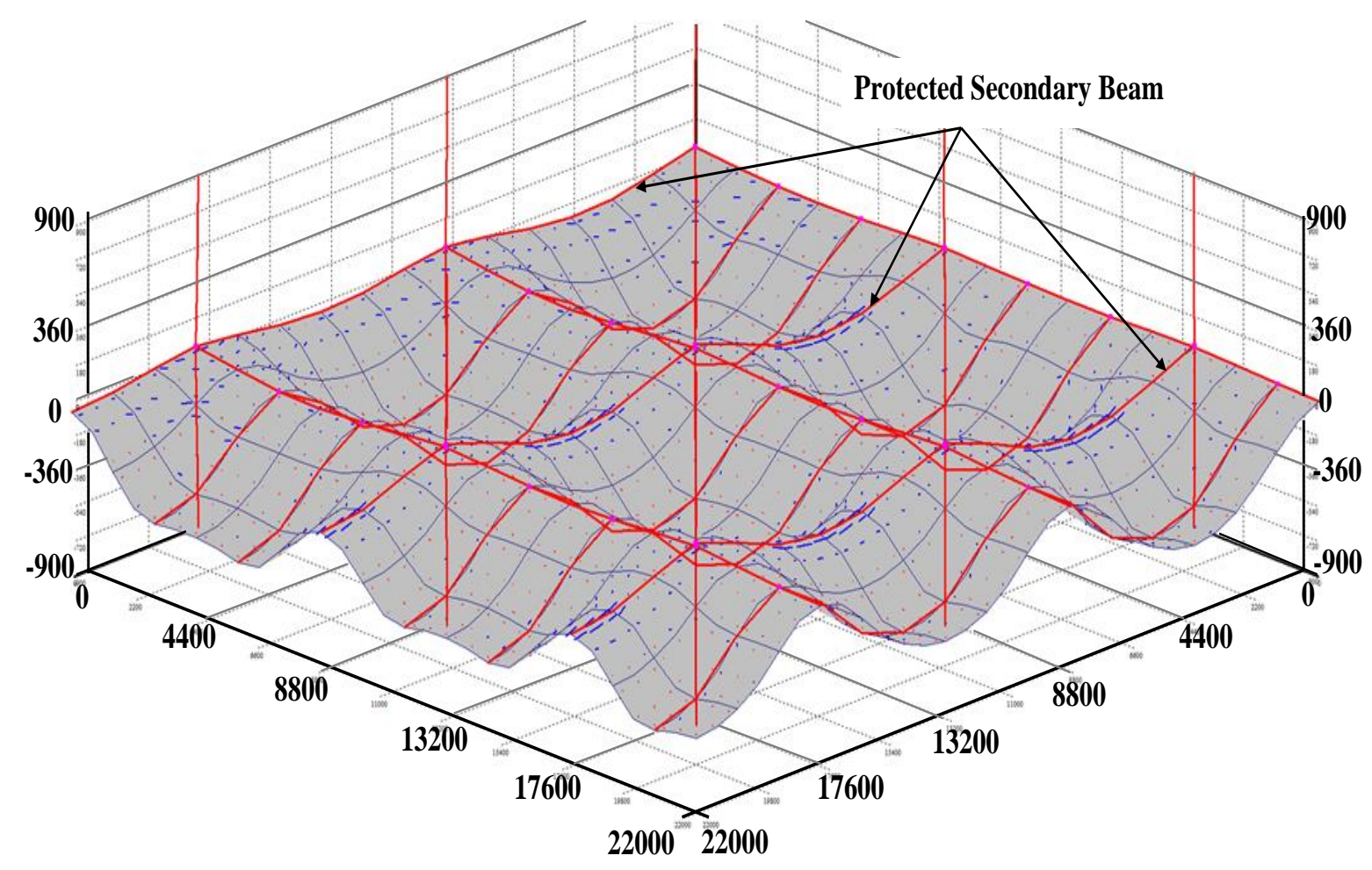

Fig. 14 Deflection profiles of slab at $1008{ }^{\circ} \mathrm{C}$ (all in $\mathrm{mm}$ )

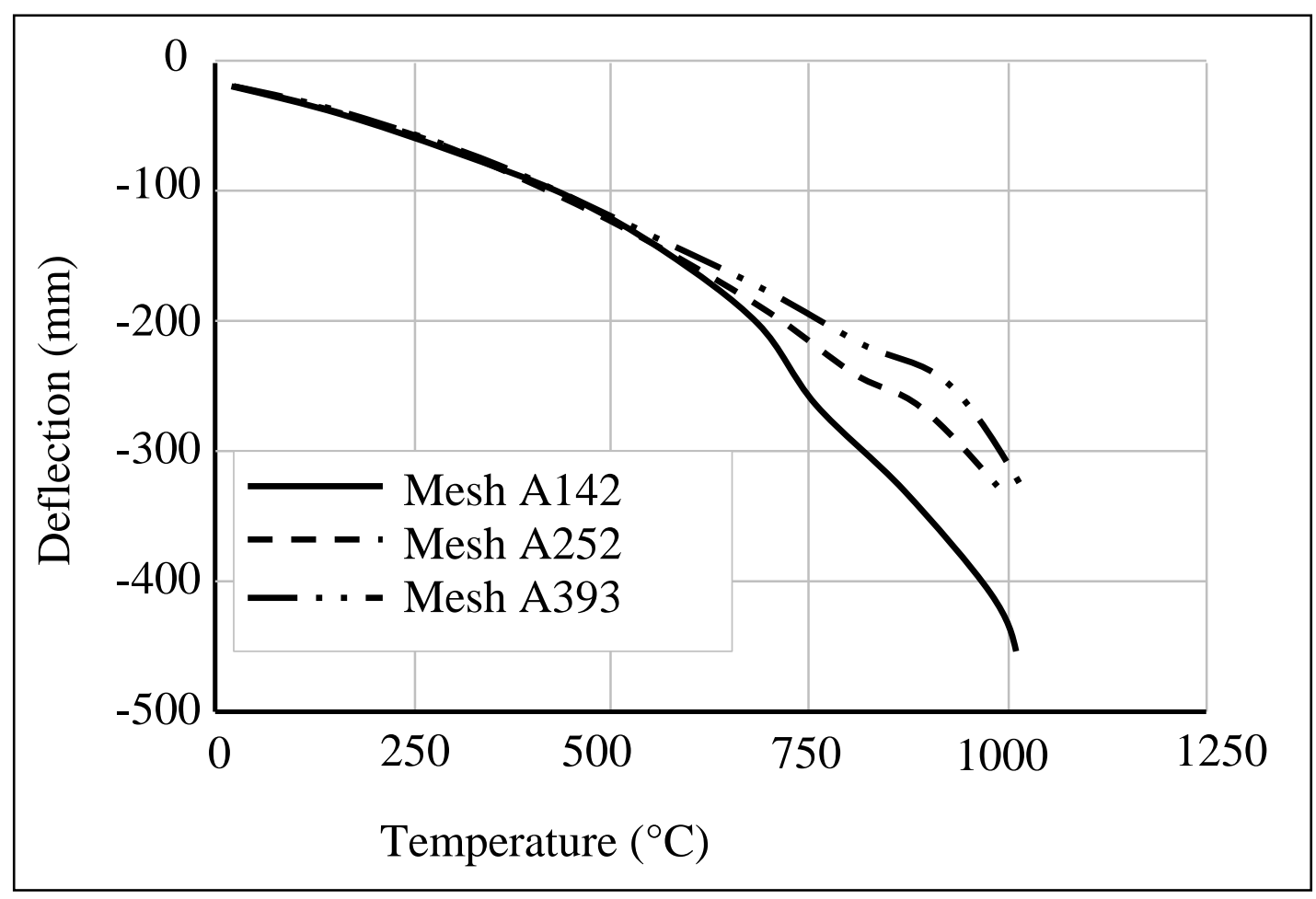

Fig. 15 Predicted deflections at position P3 under ISO Fire using different steel meshes 


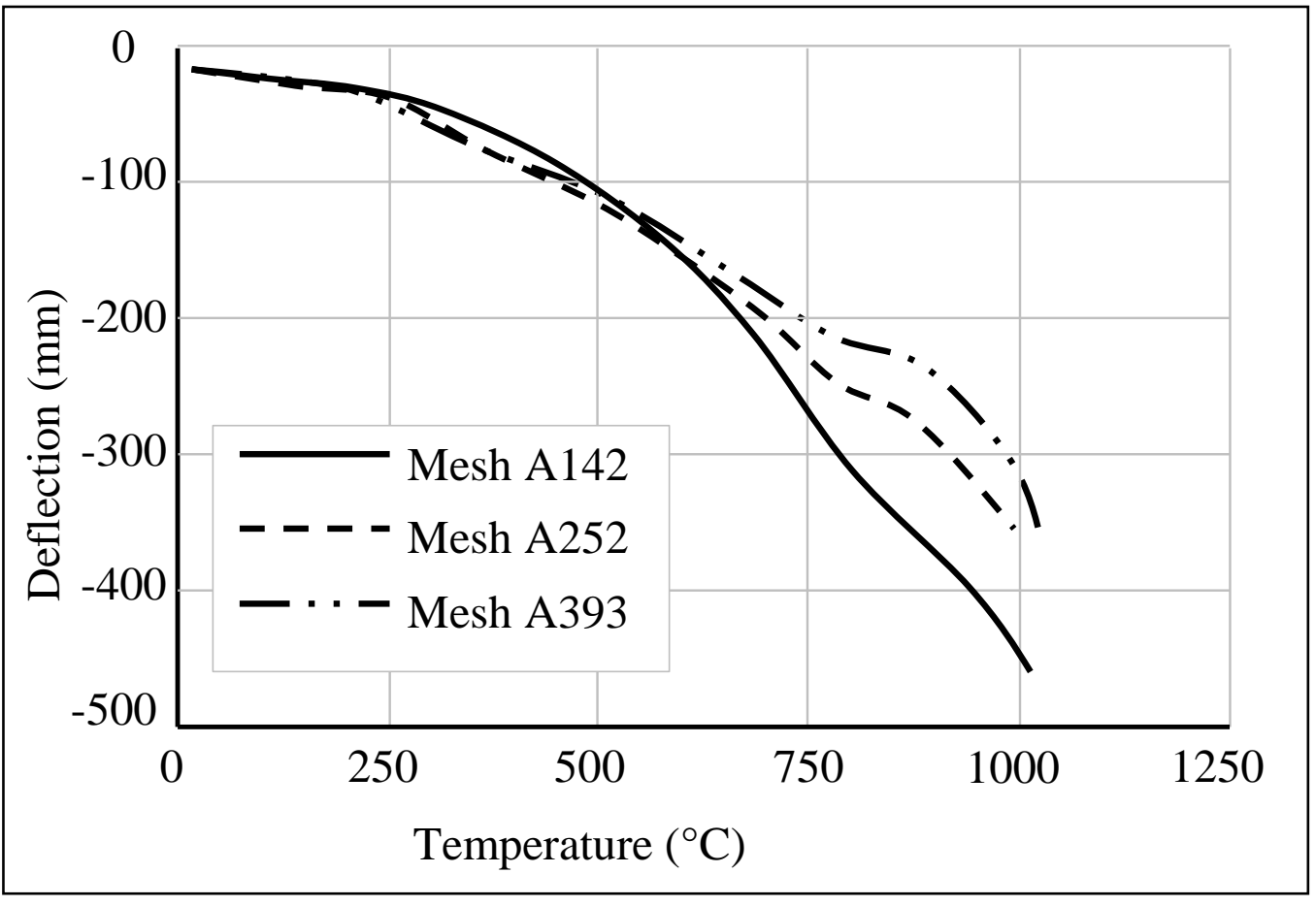

Fig. 16 Predicted deflections at position P4 under ISO Fire using different steel meshes 


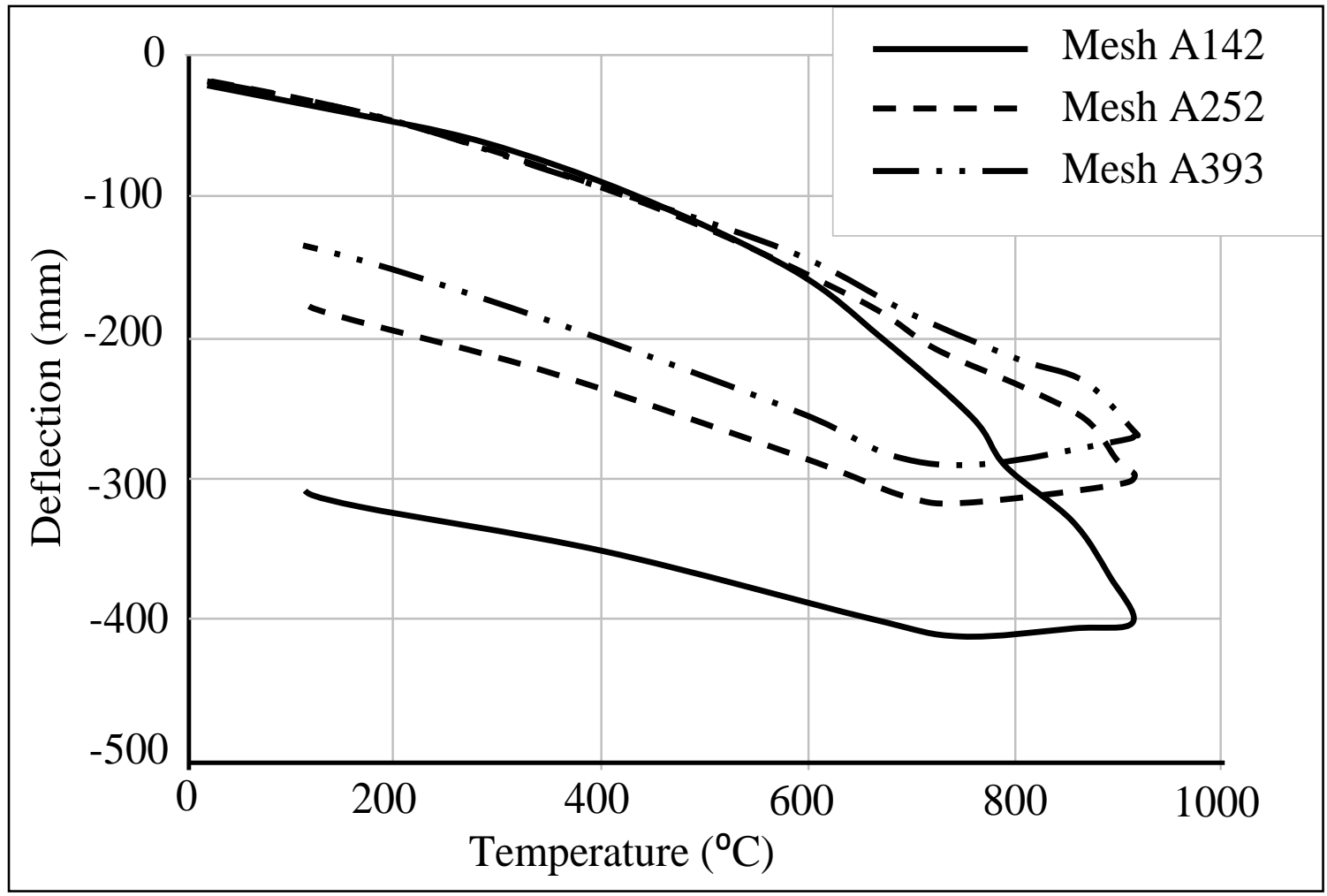

(a)

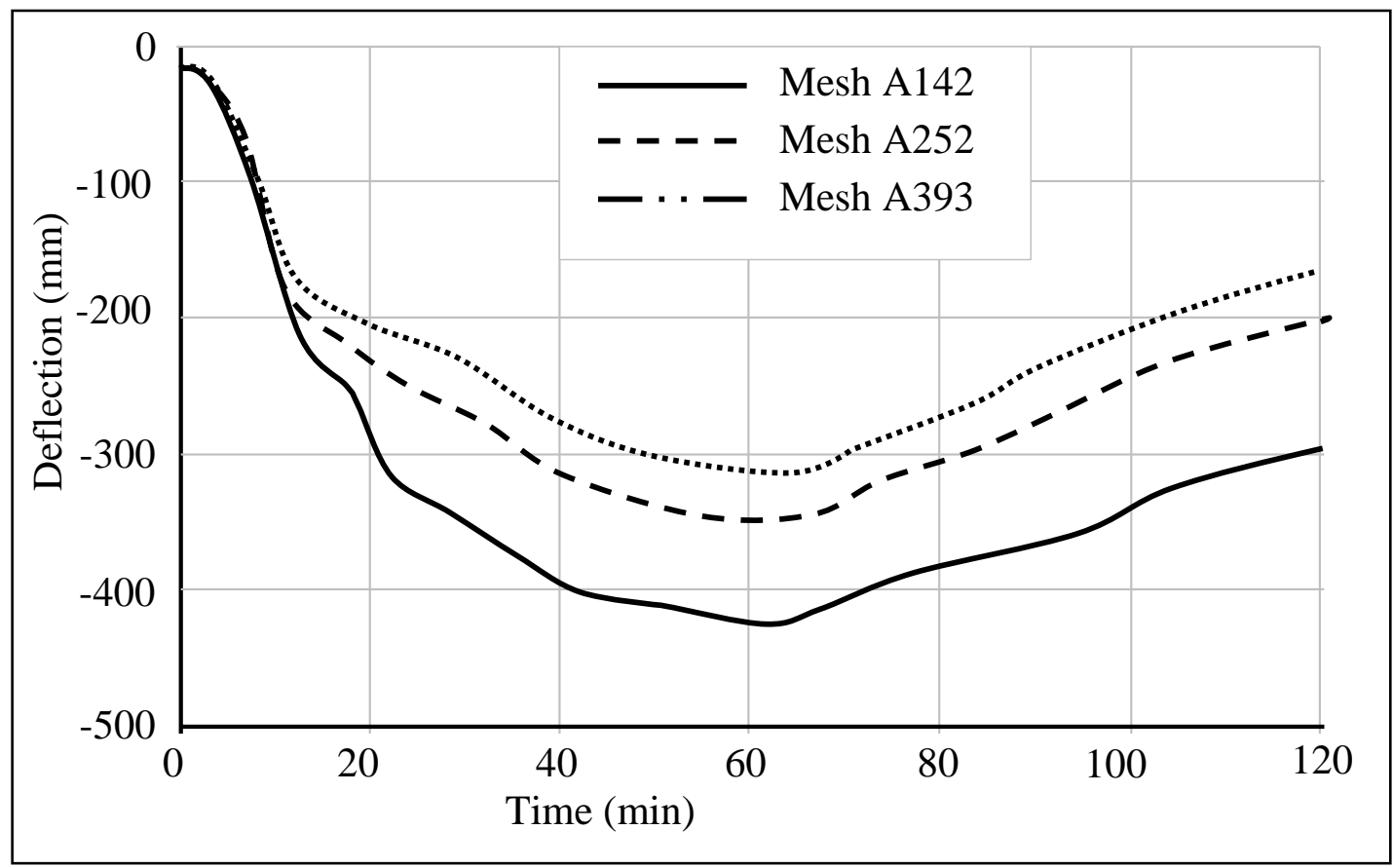

(b)

Fig. 17 Predicted deflections at position P3 under Natural Fire using different steel meshes:

(a) deflection versus beam temperatures; (b) deflection versus time 


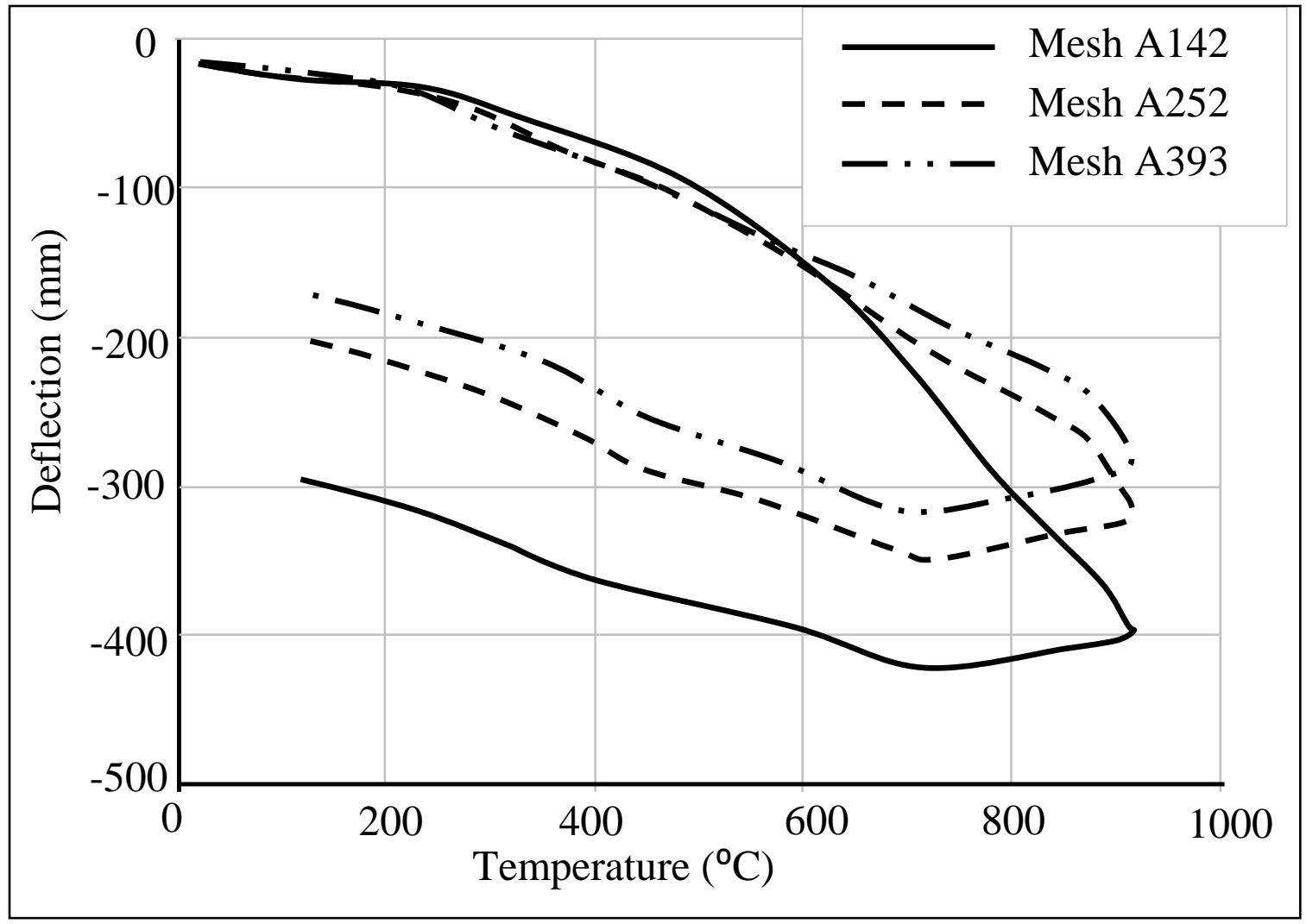

(a)

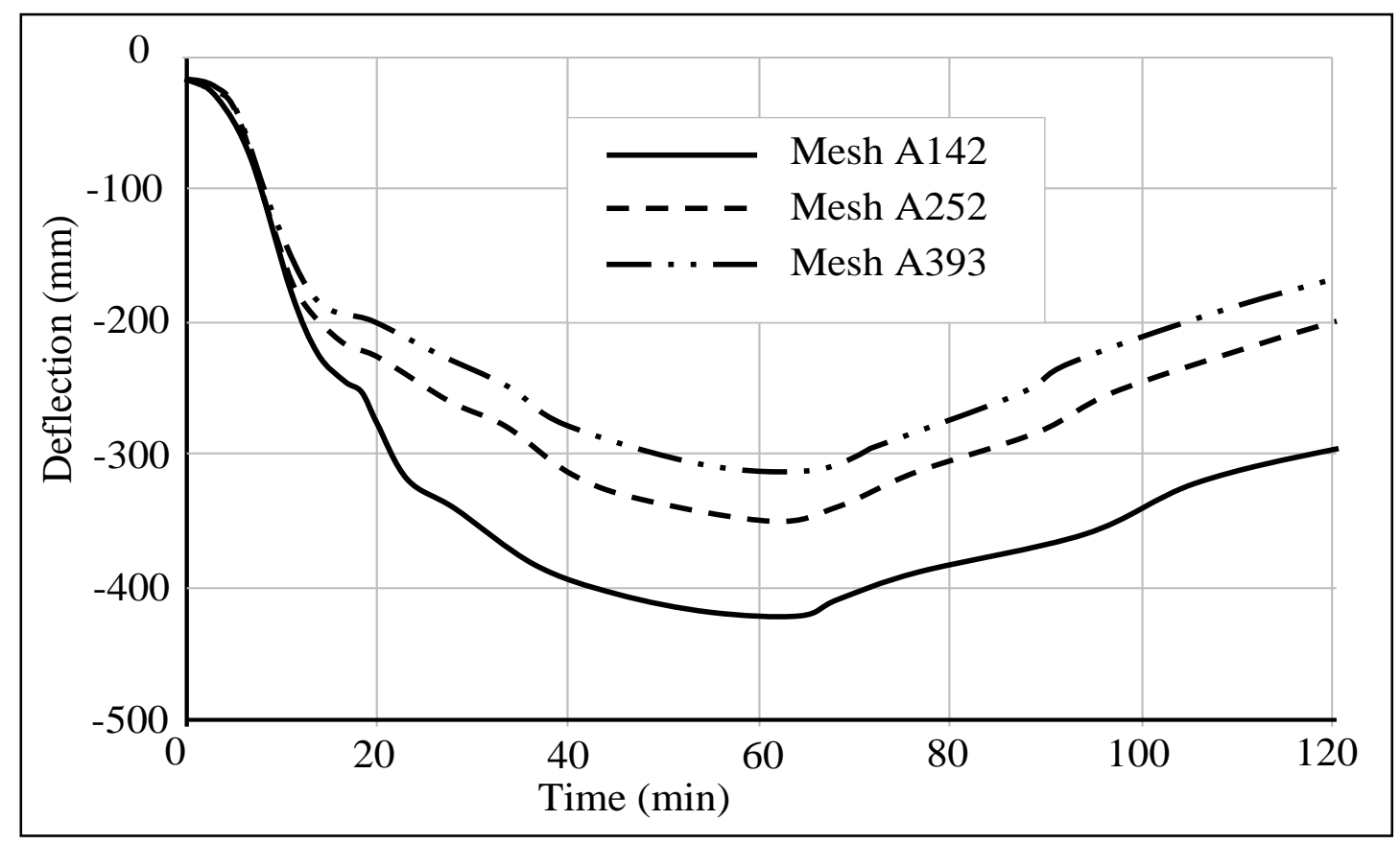

(b)

Fig. 18 Predicted deflections at position P4 under Natural Fire using different steel meshes: (a) deflection versus beam temperatures; (b) deflection versus time 


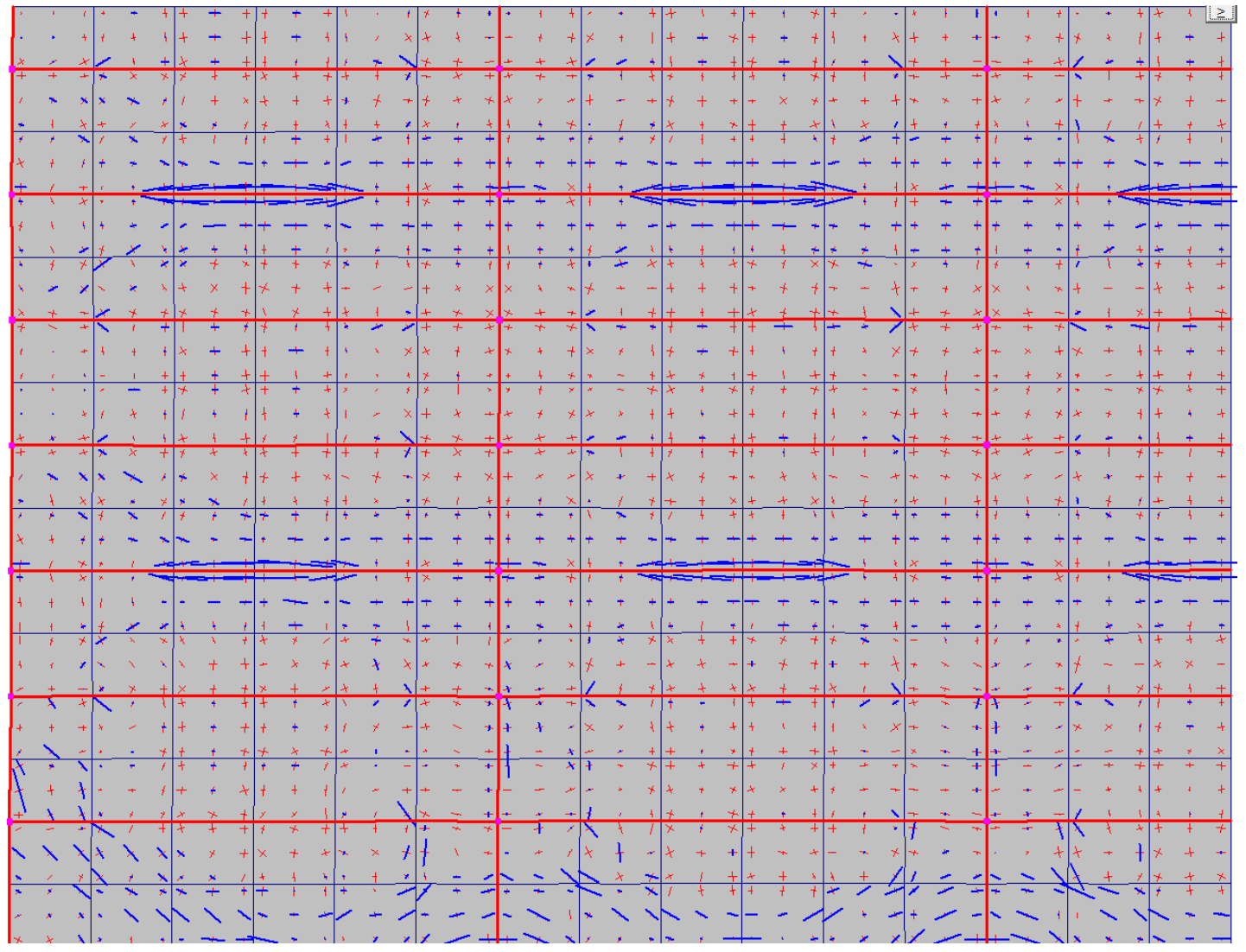

Fig. 19 Distribution of principal membrane tractions with A142 mesh at $1008{ }^{\circ} \mathrm{C}$

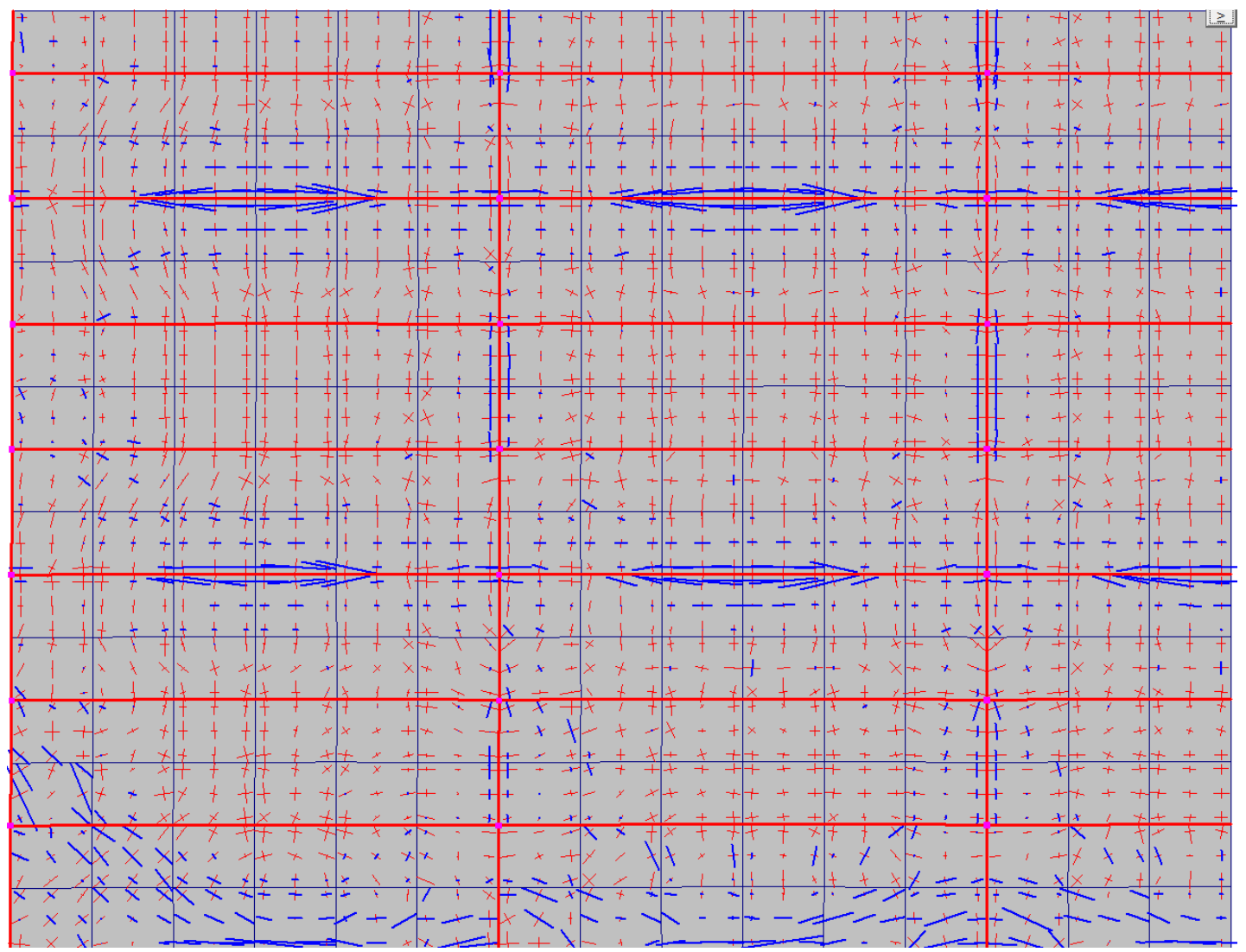

Fig. 20 Distribution of principal membrane tractions with A393 mesh at $1008{ }^{\circ} \mathrm{C}$ 


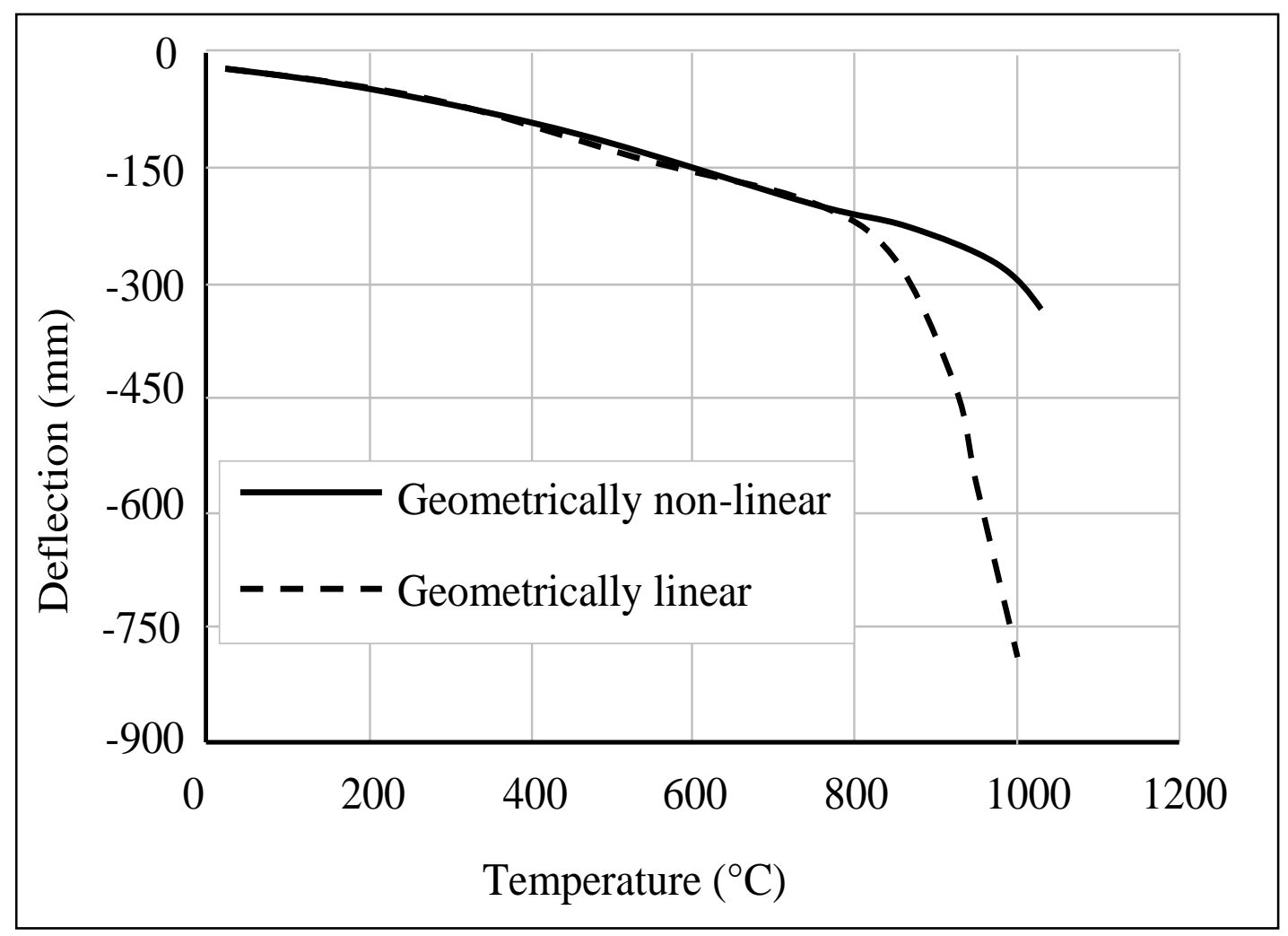

Fig. 21 Predicted deflections at position P3 using geometrically linear and non-linear procedure with A393 mesh under ISO Fire condition

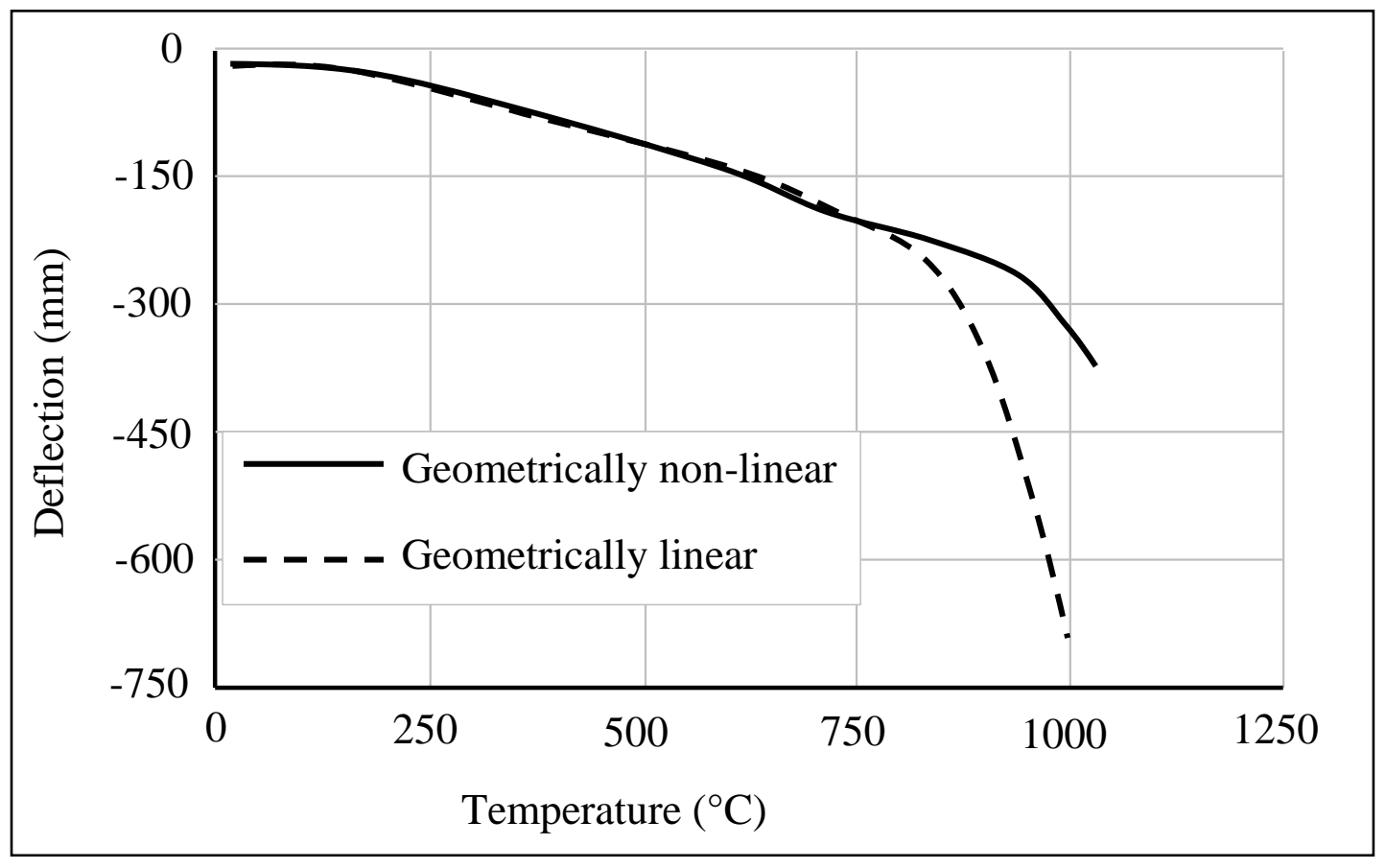

Fig. 22 Predicted deflections at position P4 using geometrically linear and non-linear procedure with A393 mesh under ISO Fire condition 


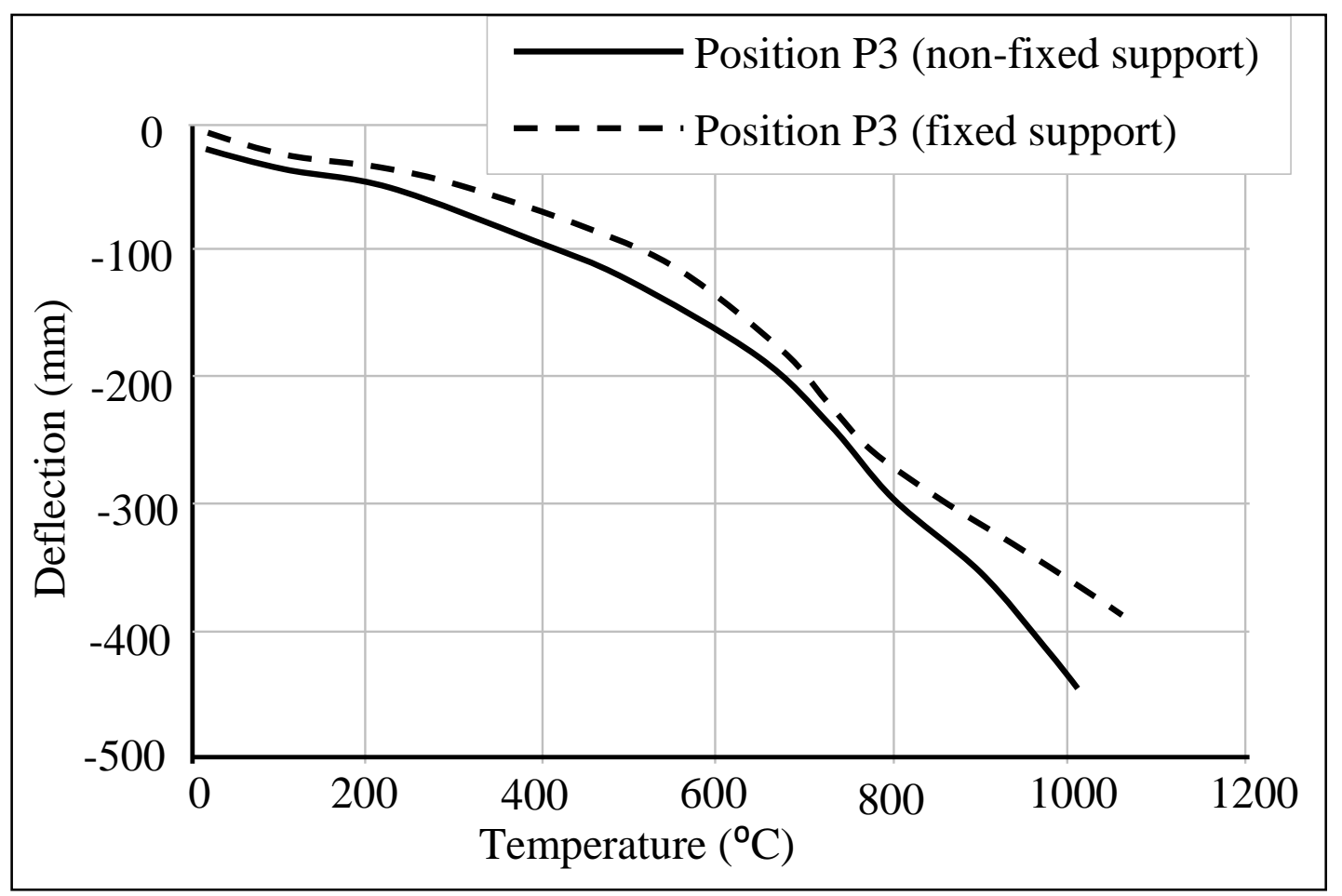

Fig. 23 Comparison of predicted deflections at positions P3 subjected to ISO Fire with nonfixed and fixed vertical support on protected steel beams (A142 mesh)

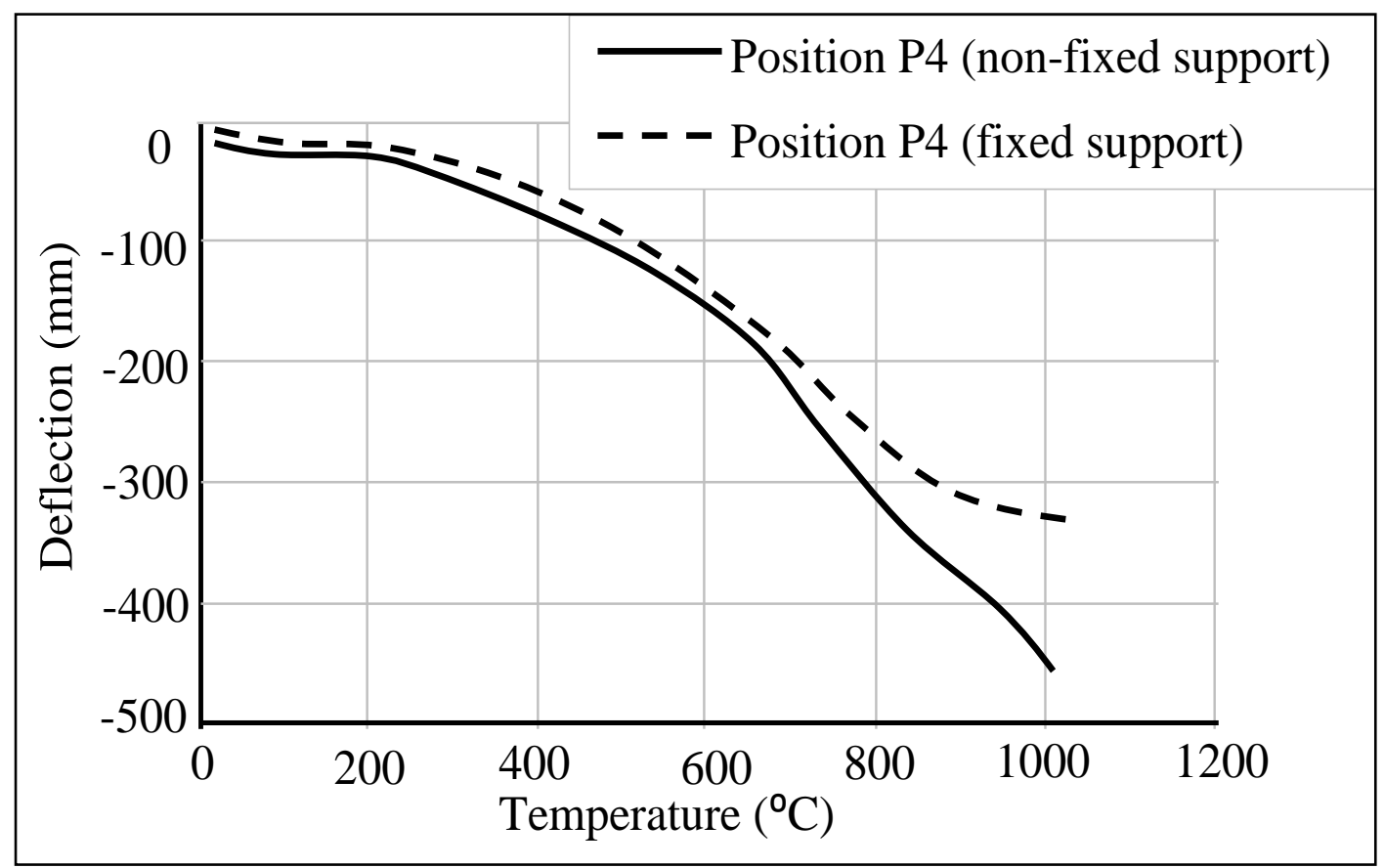

Fig. 24 Comparison of predicted deflections at positions P4 subjected to ISO Fire with nonfixed and fixed vertical support on protected steel beams (A142 mesh) 


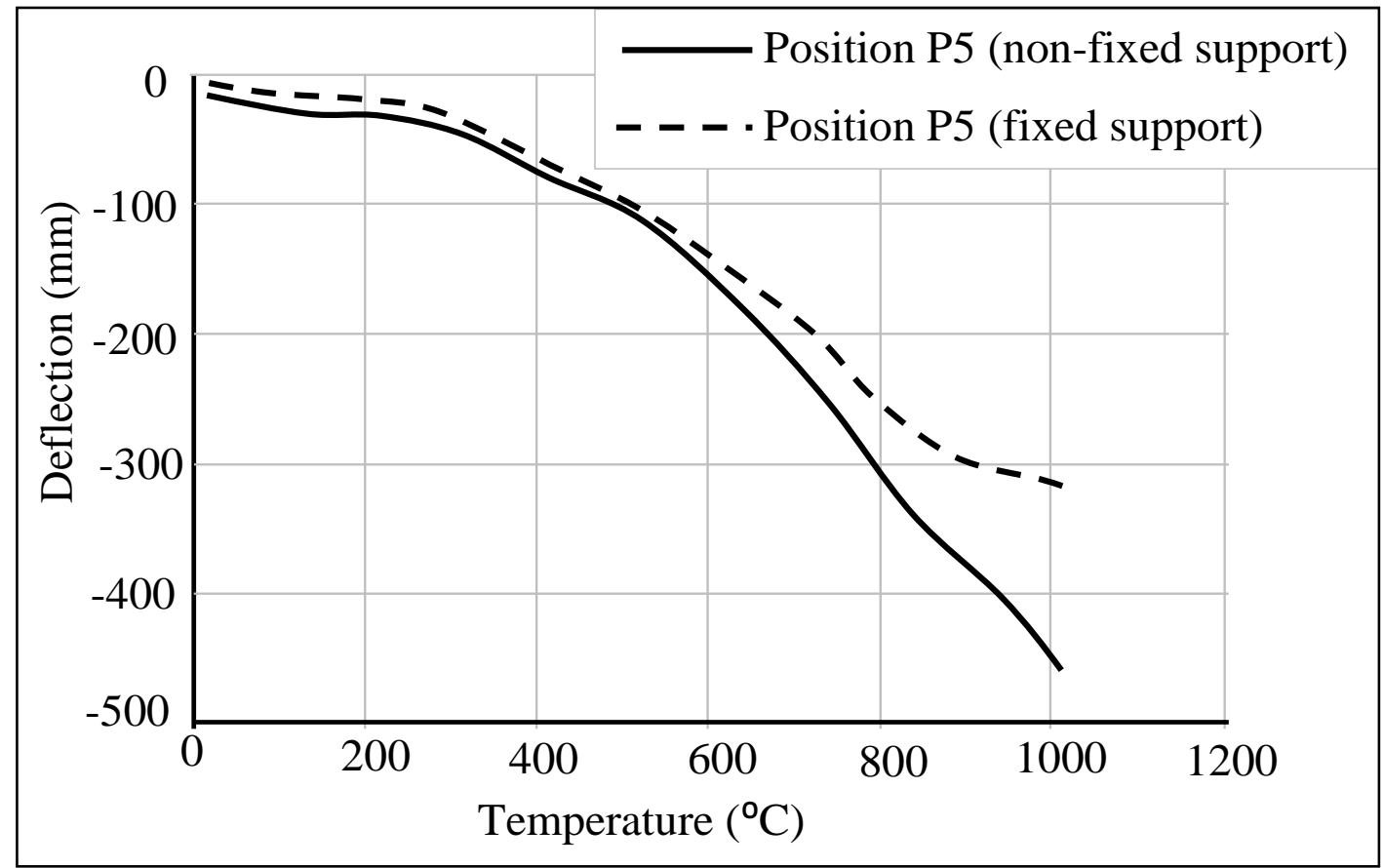

Fig. 25 Comparison of predicted deflections at positions P5 subjected to ISO Fire with nonfixed and fixed vertical support on protected steel beams (A142 mesh) 